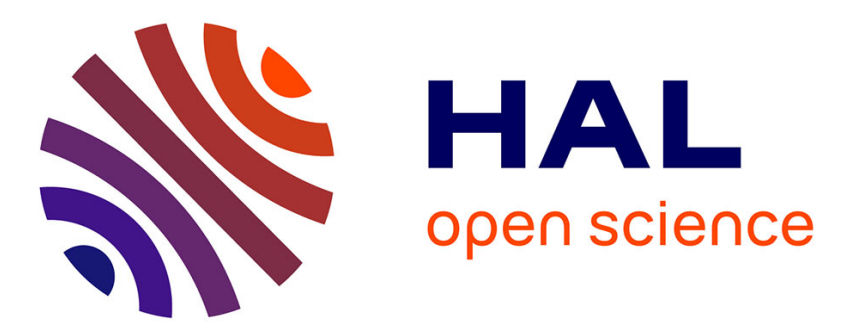

\title{
A generalized Kiselev crossover approach applied to Soave-Redlich-Kwong equation of state
} Jiri Janecek, Patrice Paricaud, Moussa Dicko, Christophe Coquelet

\section{To cite this version:}

Jiri Janecek, Patrice Paricaud, Moussa Dicko, Christophe Coquelet. A generalized Kiselev crossover approach applied to Soave-Redlich-Kwong equation of state. Fluid Phase Equilibria, 2015, 401, pp.16-26. 10.1016/j.fluid.2015.04.024 . hal-01158602

\section{HAL Id: hal-01158602 \\ https:/ /hal-mines-paristech.archives-ouvertes.fr/hal-01158602}

Submitted on 5 Jan 2016

HAL is a multi-disciplinary open access archive for the deposit and dissemination of scientific research documents, whether they are published or not. The documents may come from teaching and research institutions in France or abroad, or from public or private research centers.
L'archive ouverte pluridisciplinaire HAL, est destinée au dépôt et à la diffusion de documents scientifiques de niveau recherche, publiés ou non, émanant des établissements d'enseignement et de recherche français ou étrangers, des laboratoires publics ou privés. 


\section{A generalized Kiselev crossover approach applied to Soave-Redlich-Kwong equation of state}

Jiří Janeček ${ }^{1,2}$, Patrice Paricaud ${ }^{1}$, Moussa Dicko ${ }^{3}$ and Christophe Coquelet ${ }^{2}$ 1. UCP, ENSTA ParisTech, Université Paris-Saclay, 828 Boulevard des Maréchaux, 91762 Palaiseau Cedex, France

2. Mines ParisTech, CTP, 35 rue Saint Honoré, 77305 Fontainebleau Cedex, France

3. Univerité Paris 13, Sorbonne Paris Cité , LSPM CNRS, 99 Av Jean Baptiste Clément, 93430 Villetaneuse, France email: jiri.janecek@ensta-paristech.fr email: patrice.paricaud@ensta-paristech.fr email: moussa.dicko@lspm.cnrs.fr email: christophe.coquelet@mines-paristech.fr

\section{Abstract}

Three different variants of the crossover Soave-Redlich-Kwong equation of state are applied to describe the equilibrium behaviour of 72 common fluids - 27 hydrocarbons (including the first 10 n-alkanes), 36 halogenated refrigerants, 5 cryogenics (fluorine, oxygene, nitrogene, argon and carbon monoxide) and 4 other industrially important inorganic fluids (carbon dioxide, sulfur dioxide, nitrous oxide and sulfur hexafluoride). The model contains six compound dependent parameters; two of them ( $a_{0}$ and $b$ of the classical part) are adjusted to reproduce the critical temperature and the critical pressure. Within the first approach (model A), the remaining four parameters - the softness of dispersion interactions $m$ and three parameters of the crossover part $\left(G_{i}, d_{1}\right.$ and $\left.v_{1}\right)$ - are optimized to reproduce the coexistence densities and the saturation pressure over the whole vapor-liquid region and also the pressure along the critical- and one supercritical isotherms. In the second model (model B), mutual relation between two of the crossover parameters is employed $\left(v_{1}=v_{1}\left(G_{i}\right)\right)$ and distersion softness $m$ is expressed as a qudratic function of acentric factor $\omega$. Using these two constrains, the crossover parameter $G_{i}$ (and also $v_{1}$ ) becomes correlated to rectlinear diameter $r_{d}$ or 
critical compression factor $Z_{c}$. It is also found, that the crossover parameter $d_{1}$ has a minor effect on the equilibrium properties. In the third model (model $\mathrm{C}$ ), this parameter is omitted and the remaining parameters are estimated from knowledge of critical properties $\left(a_{0}\right.$ and $\left.b\right)$, acentric factor $(m)$ and rectlinear diameter $\left(G_{i}\right)$. The overall quality of model $\mathrm{C}$ - which requires only the knowledge of the critical properties, acentric factor and rectlinear diameter - is worse compared to the two models with fitted parameters. However, it is superior to classical cubic equations of state as for the liquid coexistence densities and superior to equations optimized to reproduce the liquid densities (PCSAFT, CPA) as for the description in the critical region. The model $\mathrm{C}$ is applied to describe the equilibrium behaviour of two compounds not included in the parametrization, hexafluoropropene (HFO1216) and hexafluoropropene oxide (HFPO), with acceptable quality.

\section{Introduction}

An accurate description of the phase equilibria in the near critical region is required in many industrial applications, such as in the natural gas- or liquid air industries, or - the most prominent example - supercritical extraction (SCE) by carbon dioxide, propane or similar compounds [1]. The solubility of compounds that has to be extracted depends mainly on the density of the supercritical solvent. Thus to optimize the SCE process, one requires an equation of state that can accurately describes the pressuretempererature--volume (PVT) data and the phase behavior in near critical regions. Another perspective application represents the transcritical Rankine cycle with organic working fluids (ORC) for the conversion of the waste-, solar- or geothermal heat [2]. The performance and efficiency of ORC can be tuned by use of mixtures of fluids $[3,4]$. Good thermodynamic model can thus reduce the amount of experimental work similarly as in the case of SCE optimization.

In the vicinity of critical point, the temperature dependence of the isochoric heat capacity is described by a power law

$$
C_{v} \propto k_{\alpha 0}+k_{\alpha 1} \tau^{-\alpha}+\ldots
$$

where $\tau=T / T_{c}-1$ is the reduced temperature. The critical exponent $\alpha$ is found to have a universal value for all fluids (and for all systems belonging to the 3D Ising model class), $\alpha=+0.110 \pm 0.003$ [5]. An analysis of most of the classical equation of state (EoS) leads to the classical value, $\alpha=0$. Similarly, differences are observed for critical exponents describing the temperature 
dependence of coexistence densities $(\beta)$, isothermal compressibility $(\gamma)$, and the density dependence of pressure at $T_{c}(\delta)[5]$.

$$
\begin{aligned}
\rho_{L}-\rho_{V} & \propto k_{\beta 1} \tau^{\beta}+\ldots \\
\kappa_{T} & \propto k_{\gamma 1} \tau^{-\gamma}+\ldots \\
P-P_{c} & \propto k_{\delta 1} \rho^{\delta}+\ldots
\end{aligned}
$$

The classical values are $\beta=1 / 2, \gamma=1$ and $\delta=3$ while the universal values $\beta=0.326, \gamma=1.237$ and $\delta=4.789$ [5].

Because of the difference in the critical exponent $\beta$, classical equations of state cannot accurately describe the temperature dependence of the coexistence densities in the critical region and the temperature vs density vaporliquid curve calculated with a classical equation of state is sharper compared to the experimental one.

For cubic EoS's such as van der Waals, Soave-Redlich-Kwong (SRK), Patel-Teja or Peng-Robinson the two pure compound parameters can be determined from the critical temperature and pressure. Due to the shape of the classical coexistence curve, the liquid densities are usually underpredicted at low temperatures by classical cubic EoS's. The pure component parameters of an equation of state can also be determined by fitting vapor pressures and saturated liquid densities, as well as PVT data. For this way of parametrization, the incorrect shape of the coexistence curve results into the overestimation of the critical temperature and pressure.

Two approaches that improve the description of fluids in the vicinity of critical points have been suggested. The first one is based on the work of White and coworkers [6,7], who suggested a recursive procedure directly based on the renormalization group theory. This method is rather demanding in terms of computational time due to required numerical integrations. It has been successfully applied to several cubic as well as non cubic equations of state $[8,9,10]$.

The other approach was developed by Kiselev and co-workers and it is based on Chen and Tang crossover models [11, 12], The method incorporates the asymptotic behaviour with the correct critical exponents and can be applied to any classical equation of state. This approach was applied to several equations of state for fluid and fluid mixtures [13, 14, 15, 16, 17, 18] including equations for associating compounds [19, 20, 21, 22]. However, most of these works suffer from the following drawbacks: (i) the crossover schemes are continuously modified and improved and it is difficult to find one crossover model applied to a large variety systems and (ii) each model applied to relatively small ensemble of compounds, having usually rather similar character. 
Our aim is to develop a crossover version of the cubic plus association equation of state (CPA) [23, 24], that can treat a broad variety of species. Already the optimization of the 5 parameters (for associating compounds) of the classical CPA EoS is problematic as rather different sets of parameters can be obtained depending on the definition of the objective function. When a crossover procedure is applied to such an equation of state, two or three additional pure component parameters must be optimized, leading to different sets of parameters that can vary of several orders of magnitude or have completely unphysical values. One way of reducing the total number of parameters consists on treating many compounds and determining some universal correlations between the parameters.

In this work, as the first step, we apply two different 3-parameter crossover schemes to describe the phase behaviour of 72 selected non-associating compounds, and investigate the sensibility of the crossover parameters and their dependence on usual pure compound properties. We also analyse the previously suggested mutual relations between the parameters of the crossover part and their dependence on the shape of VLE curve characterized by acentric factor and/or rectilinear diameter.

\section{Theory}

\subsection{Classical Equation of State}

The Soave-Redlich-Kwong (SRK) EoS is a modification of the Redlich-Kwong EoS and can be written as [25]

$$
P=\frac{R T}{v-b}-\frac{a(T)}{v(v+b)}
$$

where the temperature dependence of attraction parameter is expressed as

$$
a(T)=a_{0}\left[1+m\left(1-\sqrt{T_{r}}\right)\right]^{2}
$$

where $T_{r}=T / T_{c}$ is the reduced temperature and $m$ a compound specific parameter. Since at the critical temperature $a\left(T_{c}\right)=a_{0}$, the parameters $a_{0}$ and $b$ are related to the critical temperature and critical pressure as

$$
a_{0}=\frac{0.4275 R^{2} T_{c}^{2}}{P_{c}}
$$

and

$$
b=\frac{0.08664 R T_{c}}{P_{c}}
$$


Although the SRK EoS is a three-parameter equation of state, it always predicts the same value of the compression factor at the critical point, $Z_{c}=$ $P_{c} v_{c} / R T_{c}=1 / 3$. As a result, the critical volume is usually overestimated.

The Helmholtz free energy of the SRK EoS is given by

$$
A_{S R K}^{*}=\ln \frac{v}{v-b}-\frac{a(T)}{R T b} \ln \frac{v+b}{v}-\ln v
$$

This expression includes also the ideal gas contribution, $A_{i . g}^{*}=-\ln v=\ln \rho$.

Since the parameters $a_{0}$ and $b$ are determined from the critical properties, the parameter $m$ is the only parameter that can affect the shape of vaporliquid coexistence. This parameter can be expressed as a function of acentric factor defined as $\omega=-\log _{10} P_{0.7 T c} / P_{c}-1$. The original formula suggested by Soave is [26]:

$$
m=0.480+1.574 \omega-0.175 \omega^{2}
$$

As it will be shown later in this paper, this expression should be changed when the SRK EoS is coupled with the crossover scheme to lead to a better description of coexistence densities.

\subsection{Crossover model}

Kiselev suggested a method to incorporate the singular asymptotic behaviour into any classical equation of state and minimize the differences between the critical properties calculated from the classical EoS (critical temperature $T_{c 0}$, pressure $P_{c 0}$ and volume $v_{c 0}$ ) and the corresponding experimental values $\left(T_{c}, P_{c}, v_{c}\right)$. This approach is based on a separation of the Helmholtz energy into two parts: the critical and the regular (background) contributions. The critical part of Helmholtz energy is defined as

$$
\begin{gathered}
A_{c r}^{*}(T, v)=A^{*}(T, v)-A^{*}\left(T, v_{c 0}\right)+\Delta v P^{*}\left(T, v_{c 0}\right)= \\
=A_{r e s}^{*}(T, v)-A_{r e s}^{*}\left(T, v_{c 0}\right)-\ln (\Delta v+1)+\Delta v P^{*}\left(T, v_{c 0}\right)
\end{gathered}
$$

where $\Delta v=\left(v / v_{c 0}-1\right)$; the reduced pressure is defined as $P^{*}\left(T, v_{c 0}\right)=$ $P\left(T, v_{c 0}\right) v_{c 0} / R T$. The critical part of the Helmholtz free energy has two following properties: (i) it is zero along the critical isochore $\left(v=v_{c 0}\right)$ and (ii) its second derivative with respect to density is proportional to the isothermal compressibility. The regular part is the sum of the remaining terms

$$
\begin{gathered}
A_{r e g}^{*}(T, v)=A^{*}(T, v)-A_{c r}^{*}(T, v)= \\
=A_{r e s}^{*}\left(T, v_{c 0}\right)-\Delta v P^{*}\left(T, v_{c 0}\right)-A_{0}^{*}(T)-\ln v_{c 0}
\end{gathered}
$$


where $A_{0}^{*}(T)$ is the temperature dependent part of the Helmholtz free energy for ideal gas.

The critical contribution is reexpressed as a function of the reduced temperature and volume distance from the critical point, $\tau=\left(T / T_{c}-1\right)$ and $\eta=\left(v / v_{c}-1\right)$, and expanded into the Landau expansion [11]. Suitable rescaling of the temperature and volume variables in the critical part can enforce the thermodynamic properties to obey the correct asymptotic behaviour. Kiselev suggested the following form

$$
\bar{\tau}=\tau Y(q)^{\frac{-\alpha}{2 \Delta}}+(1+\tau) \Delta \tau_{c} Y(q)^{\frac{2(2-\alpha)}{3 \Delta}}
$$

and

$$
\bar{\eta}=\eta Y(q)^{\frac{\gamma-2 \beta}{4 \Delta}}+(1+\eta) \Delta v_{c} Y(q)^{\frac{(2-\alpha)}{2 \Delta}}
$$

where $\Delta \tau_{c}=\left(T_{c} / T_{c 0}-1\right)$ is the reduced difference between the true critical temperature $T_{c}$ and the critical temperature calculated using the classical EoS, $T_{c 0}$, analogously $\Delta v_{c}=\left(v_{c} / v_{c 0}-1\right)$ for the difference in critical volumes. The crossover function $Y(q)$ of the reduced distance from the critical point, $q$, is calculated from the main equation of parametric model, as we will show at the end of this section (eq. 19).

Finally, the renormalized Helmholtz free energy is given as a sum of the critical part calculated at the rescaled variables $\bar{T}$ and $\bar{v}$, and the background part calculated at $T$ and $v_{c 0}$

$$
\begin{gathered}
A(T, v)=A_{c r}^{*}(\bar{T}, \bar{v})+A_{r e g}^{*}\left(T, v_{c 0}\right)= \\
=A_{r e s}^{*}(\bar{T}, \bar{v})-A_{r e s}^{*}\left(\bar{T}, v_{c 0}\right)-\ln (\bar{\eta}+1)+\Delta v P^{*}\left(\bar{T}, v_{c 0}\right)
\end{gathered}
$$

The rescaled variables $\bar{T}$ and $\bar{v}$ are calculated with respect to the classical critical point, $\bar{T}=T_{c 0}(1+\bar{\tau})$ and $\bar{v}=v_{c 0}(1+\bar{\eta})$; at the experimental (true) critical point, i.e. when $T=T_{c}$ and $v=v_{c}$, the temperature and volume are equal to the classical values $T_{c 0}$ and $v_{c 0}$, and the first and second volume derivatives of pressure are equal to zero. Far from the critical point, the crossover function $Y(q)$ tends to unity and the rescaled temperature becomes $\bar{T}=T$ and $\bar{v}=v$.

The pressure is obtained from the volume derivative of the Helmholtz free energy

$$
P=-\frac{R T}{v}\left(\frac{\partial A_{c r}^{*}(\bar{T}, \bar{v})}{\partial v}\right)_{T}+P\left(T, v_{c 0}\right)
$$

where the second term is the only non-zero term from the regular part. Employing the chain rule, one can see that

$$
\frac{\partial A_{c r}^{*}(\bar{T}, \bar{v})}{\partial v}=\frac{\partial A_{c r}^{*}(\bar{T}, \bar{v})}{\partial \bar{T}} \frac{\partial \bar{T}}{\partial q} \frac{\partial q}{\partial v}+\frac{\partial A_{c r}^{*}(\bar{T}, \bar{v})}{\partial \bar{v}} \frac{\partial \bar{v}}{\partial q} \frac{\partial q}{\partial v}
$$


Since the partial derivative $\partial q / \partial v$ is equal to zero, the method of Kiselev requires the equality of the true critical pressure with that predicted by the classical EoS, $P_{c 0}=P_{c}$. This condition is satisfied for cubic EoS's, when the parameters $a$ and $b$ are determined directly from the values of the critical temperature and pressure (eq. 7 and 8 for SRK). When the pure component parameters of a classical EoS are optimized to coexistence data at low temperatures, the critical pressure is always overestimated, although the temperature dependence of the vapor pressure is well described.

Consequently, it is not possible to use the Kiselev approach and keep the parameters in the classical part of EoS unchanged, to get an accurate description of the data in the near critical region. When the Kiselev method is applied to a non cubic EoS, the classical part has to be re-parametrized in such a way that the condition $P_{c 0}=P_{c}$ is satisfied [19, 20, 21, 22]. However, the classical parameters are such that the classical part behaves in a similar way as the classical SRK Eos: the predicted critical temperature and pressure, $T_{c 0}$ and $P_{c 0}$, coincide with the experimental values but the coexistence liquid densities are systematically underpredicted. One can note that the second term in eq. 13 cancells for pure fluids as $T_{c}=T_{c 0}$.

The crossover function $Y(q)$ should approach unity far from the critical point, i.e for $q \rightarrow \infty$. For $q \rightarrow 0$ it should vanish as $q^{2 \Delta}$. In this work, we employ one of the most popular forms for the crossover function $Y(q)$

$$
Y(q)=\left(\frac{q}{q+1}\right)^{2 \Delta}
$$

The temperature change in case of this form is rather slow and the behaviour of liquid close to the triple point is affected by the critical contribution. However this is an advantage in our case, bacause this effect acts as a volume translation over the whole coexistence region and corrects underprediction of saturated liquid densities by the classical SRK EoS.

Previously, several modifications have been suggested to make the crossover function go more rapidly towards unity either by multiplication of the reduced distance $q$ by a rapidly growing function of temperature [27] or by choosing different functional form of $Y(q)[28,29]$. These modifications were used in connection with the Peng-Robinson or Patel-Teja EoS that lead to more accurate predictions of saturated liquid densities at low temperatures compared to the SRK EoS.

In this work, the distance from the critical point $q$ is calculated iteratively from the parametric sine model [30]

$$
\left(q^{2}-\frac{\tau}{G i}\right)\left[1-\frac{p^{2}}{4 b^{2}}\left(1-\frac{\tau}{q^{2} G i}\right)\right]=\left\{\frac{b f(\eta, \tau)}{m_{0} G i^{\beta}}\right\}^{2} Y^{(1-2 \beta) / \Delta}
$$


The universal parameters $p=b=\sqrt{1.359}$ is adopted from the linear model. The compound specific parameter $G_{i}$ is called the Ginzburg number, $m_{0}$ is another parameter than be considered as either universal or compound specific.

The empirical function $f(\eta, \tau)$ is introduced to eliminate the symmetry with respect to the order parameter $\eta$. In this work we employ the form used in 'generalized cubic' EoS of Kiselev and Ely [16, 31]

$$
f(\eta, \tau)=\eta\left(1+v_{1} e^{-10 \eta}\right)+d_{1} \tau
$$

In their first work using the sine model [16], the authors considered $m_{0}=$ 0.852 as universal parameter and supposed that the parameters $v_{1}=v_{1}\left(Z_{c}\right)$, $d_{1}=d_{1}\left(Z_{c}\right)$ and $G_{i}=G_{i}\left(\omega, Z_{c}, M_{w}\right)$ are compound dependent. With respect to relatively small ensemble of studied compounds (11 alkanes, 10 alcohols, 6 refrigerants and 6 cryogenics), we are not very confident in the three-variable correlation of the Ginzburg number. In the subsequent work, the crossover EoS was employed to describe the thermodynamic and transport properties of water, carbon dioxide, methane and ethane [31]. In that case, all 4 crossover parameters $\left(m_{0}, G_{i}, d_{1}\right.$ and $\left.v_{1}\right)$ were treated as compound specific. The same model later was used by Lee et al. [32] who described the equilibrium behaviour of carbon dioxide and linear alkanes keeping $m_{0}=1$ and fitting the 3 remaining parameters. However, none of the three fitted parameters could be correlated to some common properties like molar mass or acentric factor. In this work, we aim to find some trends for the crossover parameters and thereby to reduce the number of independent compound specific parameters.

\section{Results and discussion}

In this work we study only compounds included in the Refprop database [33]. For such compounds, the pseudoexperimental VLE- and PVT- data can be calculated from multiparameter Span-Wagner-like equations of state. This restriction is motivated by the sensitivity of the crossover EoS parametrization to the quality (and amount) of the input data. The studied pure compounds and their critical properties are listed in Tables 1 and 2. The reported critical properties are calculated from the corresponding Span-Wagner EoS's and these values are usually within the uncertainity range of experimentally measured critical properties.

The acentric factors and rectilinear diameters are given in Tables 3 and 4 , together with the triple point temperatures $T_{t}$, the lowest temperature for VLE data, $T_{0}$, and the literature source for the particular Spar-Wagner EoS. The VLE data used for the determination of the pure component parameters 
cover the interval between $T_{0}$ and the critical temperature in regular steps of $5 \mathrm{~K}$. In addition to these VLE data we included also PvT-data along the critical isotherm and along another isotherm above the critical temperature; this temperature was the closest integer-multiple of $50 \mathrm{~K}$ which was more than $35 \mathrm{~K}$ above $T_{c}$ (e.g. $T_{2}=350 \mathrm{~K}$ for ethane with $T_{c}=305.32 \mathrm{~K}$, but $T_{2}=500 \mathrm{~K}$ for butane with $T_{c}=425.13 \mathrm{~K}$ ). If the Span-Wagner EoS does not allow calculations at such temperature, we took simply the maximal limit of this EoS (e.g. in the case of long alkanes). These PvT-data were in steps of $1 \mathrm{MPa}$ up to $3 \times$ the value of critical pressure or up to the limit of Span-Wagner EoS.

The rectlinear diameters reported in Tables 3 and 4 were approximated as

$$
r_{d}=-\left(\frac{T_{c}}{\rho_{c}}\right) \frac{\rho_{c}-\overline{\rho_{0}}}{T_{c}-T_{0}}
$$

where $\overline{\rho_{0}}=0.5\left(\rho^{v a p}+\rho^{l i q}\right)$ is the average of coexistence densities at the lowest temperature $T_{0}$; we notice that $\rho^{v a p}$ is usually negligible compared to $\rho^{l i q}$. For an arbitrary compound, the knowledge of critical temperature and critical density and of one value of the coexistence density at low temperature is required to determine the rectlinear diameter. Thus, for any compound for which one knows $Z_{c}$ or $\omega$, the rectlinear diameter can also be evaluated.

The systematic names of the studied halogenated refrigerants can be found in Table 5. In the text we use the shorter abbreviations (used also in Refprop) instead of the RCN codes in which the letters indicate the class of refrigerant.

Since the parameters $a_{0}$ and $b$ are related to the critical temperature and pressure irrespective of the employed crossover scheme, we calculated them directly from the (pseudo)experimental $T_{c}$ and $P_{c}$ listed in Tables 1 and 2.

\section{$3.1 \quad$ Model A}

As the first step, we optimized the $m$-parameter and the three parameters of the crossover part, $G_{i}, d_{1}$ and $v_{1}$, by minimizing the objective function defined as a sum of quadratic relative deviations of saturated pressures, vapor- and liquid densities and of the PvT data

$$
\begin{aligned}
F_{\text {obj }} & =\sum_{i}\left(\frac{P_{s}\left(T_{i}\right)}{P_{s}^{\text {Refprop }}\left(T_{i}\right)}-1\right)^{2}+\sum_{i}\left(\frac{\rho_{L}\left(T_{i}\right)}{\rho_{L}^{\text {Refprop }}\left(T_{i}\right)}-1\right)^{2}+ \\
& +\sum_{i}\left(\frac{\rho_{V}\left(T_{i}\right)}{\rho_{V}^{\text {Refprop }}\left(T_{i}\right)}-1\right)^{2}++\sum_{j_{P V T}}\left(\frac{P_{j}}{P_{j}^{\text {Refprop }}}-1\right)^{2}
\end{aligned}
$$


The results of this optimization of 4 parameters will be called 'Model A'.

For most compounds, Model A provides an excellent description of the Refprop data. The average absolute deviations are listed in the first columns of Tables 6 and 7. Generally, larger deviations can be found for fluids with highly nonspherical and/or polar molecules. Large deviations can be seen for toluene (polar molecule and broad coexistence region) and propylcyclohexane (nonspherical molecule and broad coexistence region). We can also observe an increase of AAD's for the liquid density of linear alkanes of higher molecular weight. The strongest deviations are observed for fluoroethane (R161) and perfluoropentane.

The optimal values of the dispersion softness $m$ are plotted against the acentric factor $\omega$ in Figure 1. These values are systematically higher compared to the Soave's correlation for classical SRK EoS [26] (eq. 10) which is shown as the dashed line in Figure 1. The $m$ parameter for crossover model can be correlated as a quadratic function of the acentric factor

$$
m=0.5188+1.4705 \omega+0.5181 \omega^{2}
$$

Few compound slightly deviate from the correlation curve. Besides the six refrigerants highlighted in Figure 1, systematic deviations are observed for higher linear alkanes (the three right-most black circles corresponding to noctane, n-nonane and n-decane). Taking into account only the n-alkanes, we obtain correlation

$$
m=0.5084+1.6860 \omega-0.16407 \omega^{2}
$$

which is shown as the dotted line in Figure 1. Although the quality of this n-alkane correlation seems to be for most compounds the same or better compared to the global fit (except for R161, R236ea and perfluoropentane), in next steps we employed the first one, eq. 23.

No reasonable correlation can be proposed between the crossover parameters and some pure compound properties. This is illustrated by the dependence of optimized parameter $G_{i}$ on acentric factor, rectlinear diameter or critical compression factor shown in the upper parts of Figures 2, 3 and 4. The values of $v_{1}$ and $d_{1}$ are also rather scattered.

\subsection{Model B}

The crossover parameters have a smaller influence on the VLE behaviour compared to the parameters of the classical part. This is illustrated in Figure 5 where two isotherms for n-butane according to Model A are compared with calculations using different values of $v_{1}$ or $G_{i}$ parameters - one half or 
twice the optimal values; we notice that taking twice higher the value of the classical parameters $a_{0}$ or $b$ results into twice higher value of critical temperature and pressure. The parameters $v_{1}$ and $G_{i}$ have opposite effect on the isotherms - the decay of pressure caused by increase of $G_{i}$ can be compensated by decrease of $v_{1}$ and vice versa. For the mutual relation between these two parameters we decided to use a relation suggested by Kiselev [21]

$$
v_{1}=v_{1}^{(1)}+\frac{v_{1}^{(2)}}{G_{i}}
$$

where $v_{1}^{(1)}=-4.9 \times 10^{-2}$ and $v_{1}^{(2)}=+0.5 \times 10^{-2}$.

Using these two constrains (eqs. 23 and 25) we reoptimized the crossover parameters $G_{i}$ and $d_{1}$ for all pure compounds on the same set of VLE and PVT data. The new set of parameters is denoted as 'Model B'. The $G_{i}$ parameters for Model B are plotted in the lower parts of Figures 2, 3 and 4. One can see that the correlation between parameters $G_{i}$ and $v_{1}$ restricts the Ginzburg numbers into considerably narrower interval, $0.05<G_{i}<0.10$. Moreover, linear trend is observed for the dependence on rectlinear diameter, $r_{d}$, or critical compression factor, $Z_{c}$.

The parameter $d_{1}$ for Model $\mathrm{B}$ remains rather scattered, for most compounds being of the order of $10^{-2}$; for about 10 compounds the absolute value of $d_{1}$ was found larger that 1 . This parameters is multiplied by reduced temperature distance $\tau$ in eq. 20 and thus its role is small in the vicinity of critical point. In Figure 6 we compare four different isotherms for n-butane modeled by Model B with crossover parameters $G_{i}=0.0770$ and $d_{1}=-3.68$ (solid red lines) and by the same model but with $d_{1}=0$ (dashed green lines). Except the isotherm at the highest temperature $T=500 \mathrm{~K}$ the difference is hardly observable.

\subsection{Model C}

Based on the previous observations we formulate our final model, denoted as 'Model C', which is purely predictive. The parameter $m$ is related to the acentric factor according to eq. 23. Ginzburg number $G_{i}$ is approximated as linear function of rectilinear diameter as

$$
G_{i}=0.07358 r_{d}+0.00762
$$

and $v_{i}$ is calculated through the relation 25 , while $d_{1}=0$. It should be notices that expressing $G_{i}$ as function of critical compression factor $Z_{c}$ would constitute to a model of roughly the same quality. 
The average absolute deviations for Model $\mathrm{C}$ are listed in the last columns of Tables 6 and 7. As it may be expected from Figure 6, neglecting the $d_{1}$ parameter leads mainly to increase of the deviations in the equilibrium pressures.

The comparison between models B and C and the classical SRK EoS is presented in Figures 7 and 8 for n-butane, which is one of the compounds with a high value of parameter $d_{1}$ in model $\mathrm{B}$ and thus one can expect big difference between models B and C. The classical SRK EoS is used with two sets of parameters. The first one are the parameters determined from the critical point $-a_{0}=1.40702 \mathrm{MPa} /(\mathrm{L} / \mathrm{mol})^{2}, b=0.0806767 \mathrm{~L} / \mathrm{mol}-$ and from the Soave's relation $-m=0.78930$ (green double-dash-dotted lines, denoted as 'SRK' in the Figures). The second set $-a_{0}=1.2902$ $\mathrm{MPa} /(\mathrm{L} / \mathrm{mol})^{2}, b=0.072082 \mathrm{~L} / \mathrm{mol}$ and $m=0.72358$ - was optimited to describe the coexistence densities and saturated pressures well below the critical temperature [24] (blue dash-dotted lines, denoted as 'CPA' although no association contribution is not considered for n-butane of course).

All models describe perfectly the saturation pressures in the whole temperatures range. The coexistence curve continues for CPA parameters slightly above the experimental critical temperature $\left(T_{c}^{e x p}=425.13 \mathrm{~K}\right.$ vs. $T_{c}^{C P A}=$ $436.32 \mathrm{~K})$ and consequently the critical presure is overpredicted $\left(P_{c}^{e x p}=3.796\right.$ $\mathrm{MPa}$ vs. $\left.P_{c}^{C P A}=4.3604 \mathrm{MPa}\right)$ as it can be seen in the detailed inset in Figure 7 or in the $P-\rho$ projection of the coexistence diagram in the lower part of Figure 8. The liquid densities are well represented by both the crossover models at high and moderate temperatures, but deviations are observed close to the triple point.

The phase digram for 2,3,3,3-tetrafluoropropene (R1234yf) is shown in Figure 9. Model $\mathrm{C}$ is compared with classical SRK EoS with parameter set $a_{0}=1.1019 \mathrm{MPa} /(\mathrm{L} / \mathrm{mol})^{2}, b=0.069694 \mathrm{~L} / \mathrm{mol}$ and $m=0.81122$, which enables perfect description of coexistence liquid densities $\left(A A D \Delta \rho_{L}=\right.$ $0.88 \%)$ and saturated pressures $\left(A A D \Delta P_{s}=0.15 \%\right)$ for $230 \mathrm{~K}<T<340 \mathrm{~K}$. The classical EoS again overpredicts the critical temperature, $T_{c 0}=377.40$ $\mathrm{K}$, and critical pressure, $P_{c 0}=3.901 \mathrm{MPa}$ (compared to refprop values $T_{c}=$ $367.85 \mathrm{~K}$ and $\left.P_{c 0}=3.3822 \mathrm{MPa}\right)$. Outside of the critical region - more than 30 degrees above the critical temperature, the classical EoS provides good description; even along the critical isotherm the pressure is predicted correctly for densities twice higher than the critical one. The coexistence densities directly measured by Tanaka and Hagashi [34] agree well with the refrop values.

The phase diagrams for perfluoropentane according to Models A and C are compared in Figure 10. Perfluoropentane is one of the compounds for which the Model $\mathrm{C}$ does not work optimally. This is expectable, since in both 
employed correlations (eq. 23 and 26) the optimal value for perfluoropentane is deviated (see Figs. 1 and 3).

The largest deviation at all are found for fluoroethane, R161. The phase diagram for this compound is shown in Figure 11. Systematic differences in liquid densities (and of the densities of compressed fluid) are observed between Model $\mathrm{C}$ and the Refprop data. Fluoroethane belongs between about 8 compound for which the Refprop EoS was not published yet. This is probably because of low number of available experimental data. In Figure 11 we show also coexistence densities meassured recently by Han et al [35]; these data differ considerably from the Refprop values. We are not able to decide, whether there is a problem in parametrization of the Refprop EoS because of small number of data, because of low quality of data or whether the data of Han et al are errorneous.

Finally, in Figures 12 and 13 we show the phase diagrams for hexafluoropropene (R1218) and for hexafluoropropene oxide (HFPO), two compounds not included in Refprop 9. Model $\mathrm{C}$ is compared with classical SRK EoS (adjusted to $T_{c}$ and $P_{c}$ ) and with the experimental data [36, 37]. The quality of description of HFPO is slightly worse compared to crossover Patel-Teja EoS developed in [37] however the Model $\mathrm{C}$ does not include any fitted parameters.

\section{Conclusions}

We applied the sine parametric crossover model to 72 fluids included in Refprop database. Two parameters of the classical part are related to the critical temperature and critical pressure; third classical parameter describing the temperature dependence of dispersion interactions can be expressed as a function of acentric factor. As for the parameters of the crossover part, it was found that their influence on the equilibrium behaviour is a less important compared to the three parameters of classical part. More important effect on the quality of phase diagram than the three fitted crossover parameters, $G_{i}, v_{1}$ and $d_{1}$, has the critical volume shift $\Delta v_{c}$ appearing in eq. 14, which is a compound specific parameter following from the experimental critical properties.

Using consecutive reduction of the number of fitted parameters, we arrived at a model in which two of the crossover parameters are expressed as a function of the rectlinear diameter and the third one is neglected $\left(d_{1}\right)$. This 'predictive' model enables for most studied compounds description of coexistence densities and saturation pressure which is of moderate quality. Despite of the strongest employed approximation - neglecting of parameter $d_{1}$ in the 
final model - good quality is reached at temperatures close to the critical one.

\section{Acknowledgement}

The authors would like to acknowledge the support by Carnot Mines Institute. The stay of J.J. was enabled by support of Mines Telecom Institute. 


\section{References}

[1] G. Brunner, Annu. Rev. Chem. Biomol. Eng. 1, 321 (2010).

[2] B. Liu, P. Riviere, C. Coquelet, R. Gicquel, and F. David, Applied Energy 100, 285 (2012).

[3] A. Valtz and C. Coquelet, Fluid Phase Equil. 316, 141 (2012).

[4] H. Madani, A. Valtz, and C. Coquelet, Fluid Phase Equil. 354, 109 (2013).

[5] M. A. Anisimov and J. V. Sengers, Critical region, in Equations of State for Fluids and Fluid Mixtures, edited by J. Sengers, R. Kayser, C. Peters, and H. White, pages 381-434, Elsevier, 2000.

[6] J. A. White and S. Zhang, J. Chem. Phys. 99, 2012 (1993).

[7] J. A. White and S. Zhang, J. Chem. Phys. 103, 1922 (1993).

[8] L. Lue and J. M. Prausnitz, J. Chem. Phys. 108, 5529 (1998).

[9] X. H. Xu and Y. Y. Duan, Fluid Phase Equilibria 290, 148 (2010).

[10] A. Bymaster, C. Emborsky, A. Dominik, and W. G. Chapman, Ind. Eng. Chem. Res. 47, 6264 (2008).

[11] Z. Y. Chen, A. Abbaci, and S. Tang, Phys. Rev. A 42, 4470 (1990).

[12] S. Tang, J. V. Sengers, and Z. Y. Chen, Physica A 179, 344 (1991).

[13] S. B. Kiselev, Fluid Phase Equil. 147, 7 (1998).

[14] S. B. Kiselev and D. G. Friend, Fluid Phase Equil. 162, 51 (1999).

[15] S. B. Kiselev and J. F. Ely, Fluid Phase Equil. 174, 93 (2000).

[16] S. B. Kiselev and J. F. Ely, J. Chem. Phys 119, 8645 (2003).

[17] C. McCabe and S. B. Kiselev, Ind. Eng. Chem. Res. 43, 2839 (2004).

[18] C. McCabe and S. B. Kiselev, Fluid Phase Eql. 219, 3 (2004).

[19] Z. Q. Hu, J. C. Yang, and Y. G. Li, Fluid Phase Eql. 205, 1 (2003).

[20] Z. Q. Hu, J. C. Yang, and Y. G. Li, Fluid Phase Eql. 205, 25 (2003). 
[21] S. Kiselev, J. F. Ely, H. Adidharma, and M. Radosz, Fluid Phase Eql. 183, 53 (2001).

[22] S. Kiselev, J. F. Ely, S. P. Tan, H. Adidharma, and M. Radosz, Ind. Eng. Chem. Res. 45, 3981 (2006).

[23] G. Kontogeorgis et al., Ind. Eng. Chem. Res. 45, 4855 (2006).

[24] G. Kontogeorgis et al., Ind. Eng. Chem. Res. 45, 4869 (2006).

[25] A. Anderko, Cubic and generalized van der waals equations, in Equations of State for Fluids and Fluid Mixtures, edited by J. Sengers, R. Kayser, C. Peters, and H. White, pages 75-126, Elsevier, 2000.

[26] G. Soave, Chem. Eng. Sci. 27, 1197 (1972).

[27] F. Feyzi, M. Seydi, and F. Alavi, Fluid Phase Equilibria 293, 251 (2010).

[28] L. Kudelkova, J. Lovland, and P. Vonka, Fluid Phase Equil. 218, 103 (2004).

[29] M. Dicko and C. Coquelet, Fluid Phase Eql. 302, 241 (2011).

[30] M. E. Fisher, S. Zinn, and P. J. Upton, Phys. Rev. B 59, 14533 (1999).

[31] S. B. Kiselev and J. F. Ely, Fluid Phase Equil. 222, 149 (2004).

[32] Y. Lee, M. S. Shin, J. K. Yeo, and H. Kim, J. Chem. Thermodyn. 39, 1257 (2007).

[33] E. Lemmon, M. Huber, and M. McLinden, NIST, Standard Reference Data Program, Gaithersburg (2013).

[34] K. Tanaka and Y. Higashi, Int. J. Refrig. 33, 474 (2010).

[35] X. H. Han et al., J. Chem. Eng. Data 56, 3038 (2011).

[36] C. Coquelet et al., J. Chem. Eng. Data 55, 2093 (2010).

[37] M. Dicko et al., Ind. Eng. Chem. Res. 50, 4761 (2011).

[38] U. Setzmann and W. Wagner, J. Phys. Chem. Ref. Data 20, 1061 (1991).

[39] D. Buecker and W. Wagner, J. Phys. Chem. Ref. Data 35, 205 (2006).

[40] E. Lemmon, M. McLinden, and W. Wagner, J. Chem. Eng. Data 54, 3141 (2009). 
[41] D. Buecker and W. Wagner, J. Phys. Chem. Ref. Data 35, 929 (2006).

[42] R. Span and W. Wagner, Int. J. Thermophys. 24, 41 (2003).

[43] E. Lemmon and R. Span, J. Chem. Eng. Data 51, 785 (2006).

[44] M. Thol, E. Lemmon, and R. Span, (2010).

[45] A. Polt, B. Platzer, and G. Maurer, Chem. Tech. (Leipzig) 44, 216 (1992).

[46] S. Penoncello, A. Goodwin, and R. Jacobsen, Int. J. Thermophys. 16, 519 (1995).

[47] J. Smukala, R. Span, and W. Wagner, J. Phys. Chem. Ref. Data 29, 1053 (2000).

[48] E. Lemmon and E. Ihmels, Fluid Phase Equilibria 228-229, 173 (2005).

[49] C. Guder and W. Wagner, J. Phys. Chem. Ref. Data 38, 33 (2009).

[50] K. de Reuck, International Thermodynamic Tables of the Fluid State-11 Fluorine, International Union of Pure and Applied Chemistry, Pergamon Press, Oxford (1990).

[51] R. Schmidt and W. Wagner, Fluid Phase Equilibria 19, 175 (1985).

[52] R. Span, E. Lemmon, R. Jacobsen, W. Wagner, and A. Yokozeki, J. Phys. Chem. Ref. Data 29, 1361 (2000).

[53] R. Span and W. Wagner, J. Phys. Chem. Ref. Data 25, 1509 (1996).

[54] C. Tegeler, R. Span, and W. Wagner, J. Phys. Chem. Ref. Data 28, 779 (1999).

[55] M. Huber and J. Ely, Int. J. Refrigeration 17, 18 (1994).

[56] R. Jacobsen, S. Penoncello, , and E. Lemmon, Fluid Phase Equilibria 80, 45 (1992).

[57] V. Marx, A. Pruss, and W. Wagner, Duesseldorf, VDI Verlag, Series 19 (Waermetechnik/Kaeltetechnik) 57 (1992).

[58] B. Platzer, A. Polt, and G. Maurer, Thermophysical properties of refrigerants, Springer-Verlag, Berlin (1990). 
[59] B. Younglove and M. McLinden, J. Phys. Chem. Ref. Data 23, 731 (1994).

[60] M. Richter, M. McLinden, and E. Lemmon, J. Chem. Eng. Data 56, 3254 (2011).

[61] M. McLinden, M. Thol, and E. Lemmon, International Refrigeration and Air Conditioning Conference, Purdue (2010).

[62] B. de Vries, R. Tillner-Roth, and H. Baehr, 19th International Congress of Refrigeration, The Hague, The Netherlands, International Institute of Refrigeration, IVa:582 (1995).

[63] E. Lemmon and R. Jacobsen, J. Phys. Chem. Ref. Data 34, 69 (2005).

[64] J. Magee, S. Outcalt, and J. Ely, Int. J. Thermophys. 21, 1097 (2000).

[65] R. Tillner-Roth and H. Baehr, J. Phys. Chem. Ref. Data 23, 657 (1994).

[66] E. Lemmon and R. Jacobsen, J. Phys. Chem. Ref. Data 29, 521 (2000).

[67] S. Outcalt and M. McLinden, J. Phys. Chem. Ref. Data 25, 605 (1996).

[68] A. Kamei, S. Beyerlein, and R. Jacobsen, Int. J. Thermophysics 16, 1155 (1995).

[69] S. Penoncello, E. Lemmon, R. Jacobsen, and Z. Shan, J. Phys. Chem. Ref. Data 32, 1473 (2003).

[70] S. Outcalt and M. McLinden, NIST report to sponsor (U.S. Navy, David Taylor Model Basin) under contract N61533-94-F-0152 (1995).

[71] R. Tillner-Roth and A. Yokozeki, J. Phys. Chem. Ref. Dat 26, 1273 (1997). 
Table 1: Critical properties of studied compounds. Part A.

\begin{tabular}{lccccc}
\hline \hline Compound & $T_{c}[\mathrm{~K}]$ & $P_{c}[\mathrm{MPa}]$ & $v_{c}[\mathrm{~L} / \mathrm{mol}]$ & $\rho_{c}[\mathrm{~mol} / \mathrm{L}]$ & $Z_{c}$ \\
\hline methane & 190.56 & 4.5992 & 0.0986 & 10.1390 & 0.2863 \\
ethane & 305.32 & 4.8722 & 0.1458 & 6.8569 & 0.2799 \\
propane & 369.89 & 4.2512 & 0.2000 & 5.0000 & 0.2765 \\
n-butane & 425.13 & 3.7960 & 0.2549 & 3.9228 & 0.2738 \\
n-pentane & 469.70 & 3.3700 & 0.3110 & 3.2156 & 0.2684 \\
n-hexane & 507.82 & 3.0340 & 0.3696 & 2.7059 & 0.2656 \\
n-heptane & 540.13 & 2.7360 & 0.4319 & 2.3153 & 0.2632 \\
n-octane & 569.32 & 2.4970 & 0.4863 & 2.0564 & 0.2565 \\
n-nonane & 594.55 & 2.2810 & 0.5525 & 1.8100 & 0.2550 \\
n-decane & 617.70 & 2.1030 & 0.6098 & 1.6400 & 0.2497 \\
benzene & 562.02 & 4.9063 & 0.2563 & 3.9020 & 0.2690 \\
toluene & 591.75 & 4.1263 & 0.3156 & 3.1689 & 0.2740 \\
cyclopropane & 398.30 & 5.5797 & 0.1628 & 6.1429 & 0.2743 \\
cyclopentane & 511.69 & 4.5150 & 0.2618 & 3.8200 & 0.2778 \\
cyclohexane & 553.64 & 4.0750 & 0.3083 & 3.2438 & 0.2729 \\
methylcyclohexane & 572.20 & 3.4700 & 0.3677 & 2.7200 & 0.2681 \\
propylcyclohexane & 630.80 & 2.8600 & 0.4854 & 2.0600 & 0.2647 \\
isobutane & 407.81 & 3.6290 & 0.2578 & 3.8797 & 0.2759 \\
isopentane & 460.35 & 3.3780 & 0.3057 & 3.2710 & 0.2698 \\
isohexane & 497.70 & 3.0400 & 0.3683 & 2.7150 & 0.2706 \\
neopentane & 433.74 & 3.1960 & 0.3058 & 3.2700 & 0.2710 \\
ethene & 282.35 & 5.0418 & 0.1309 & 7.6371 & 0.2812 \\
propene & 364.21 & 4.5550 & 0.1833 & 5.4570 & 0.2757 \\
butene & 419.29 & 4.0051 & 0.2359 & 4.2400 & 0.2710 \\
cisbutene & 435.75 & 4.2255 & 0.2356 & 4.2439 & 0.2748 \\
transbutene & 428.61 & 4.0273 & 0.2374 & 4.2130 & 0.2683 \\
isobutene & 418.09 & 4.0098 & 0.2398 & 4.1700 & 0.2766 \\
sulfurhexafluoride & 318.72 & 3.7550 & 0.1968 & 5.0823 & 0.2788 \\
fluorine & 144.41 & 5.1724 & 0.0641 & 15.6031 & 0.2761 \\
oxygen & 154.58 & 5.0430 & 0.0734 & 13.6295 & 0.2879 \\
nitrogen & 126.19 & 3.3958 & 0.0894 & 11.1844 & 0.2894 \\
carbonmonoxide & 132.86 & 3.4940 & 0.0922 & 10.8495 & 0.2915 \\
carbondioxide & 304.13 & 7.3773 & 0.0941 & 10.6247 & 0.2746 \\
argon & 150.69 & 4.8630 & 0.0746 & 13.4066 & 0.2895 \\
sulfurdioxide & 430.64 & 7.8840 & 0.1220 & 8.1947 & 0.2687 \\
nitrousoxide & 309.52 & 7.2450 & 0.0974 & 10.2701 & 0.2741 \\
\hline \hline
\end{tabular}


Table 2: Critical properties of studied compounds. Part B - halogenated compounds.

\begin{tabular}{lccccc}
\hline \hline Compound & $T_{c}[\mathrm{~K}]$ & $P_{c}[\mathrm{MPa}]$ & $v_{c}[\mathrm{~L} / \mathrm{mol}]$ & $\rho_{c}[\mathrm{~mol} / \mathrm{L}]$ & $Z_{c}$ \\
\hline Perfluorobutane & 386.33 & 2.3234 & 0.3968 & 2.5200 & 0.2871 \\
Perfluoropentane & 420.56 & 2.0450 & 0.4726 & 2.1160 & 0.2764 \\
R11 & 471.11 & 4.4076 & 0.2480 & 4.0331 & 0.2790 \\
R113 & 487.21 & 3.3922 & 0.3346 & 2.9887 & 0.2802 \\
R114 & 418.83 & 3.2570 & 0.2947 & 3.3932 & 0.2757 \\
R115 & 353.10 & 3.1290 & 0.2513 & 3.9799 & 0.2678 \\
R116 & 293.03 & 3.0480 & 0.2250 & 4.4440 & 0.2815 \\
R12 & 385.12 & 4.1361 & 0.2140 & 4.6729 & 0.2764 \\
R123 & 456.83 & 3.6618 & 0.2781 & 3.5963 & 0.2681 \\
R1234yf & 367.85 & 3.3822 & 0.2398 & 4.1700 & 0.2652 \\
R1234ze & 382.52 & 3.6363 & 0.2331 & 4.2900 & 0.2665 \\
R124 & 395.43 & 3.6243 & 0.2437 & 4.1032 & 0.2687 \\
R125 & 339.17 & 3.6177 & 0.2093 & 4.7790 & 0.2685 \\
R13 & 302.00 & 3.8790 & 0.1792 & 5.5800 & 0.2769 \\
R134a & 374.21 & 4.0593 & 0.1993 & 5.0171 & 0.2601 \\
R14 & 227.51 & 3.7500 & 0.1407 & 7.1093 & 0.2789 \\
R141b & 477.50 & 4.2120 & 0.2550 & 3.9210 & 0.2706 \\
R142b & 410.26 & 4.0550 & 0.2253 & 4.4379 & 0.2679 \\
R143a & 345.86 & 3.7610 & 0.1950 & 5.1285 & 0.2550 \\
R152a & 386.41 & 4.5168 & 0.1795 & 5.5717 & 0.2524 \\
R161 & 375.30 & 5.0910 & 0.1592 & 6.2798 & 0.2598 \\
R21 & 451.48 & 5.1812 & 0.1957 & 5.1109 & 0.2701 \\
R218 & 345.02 & 2.6400 & 0.2994 & 3.3400 & 0.2756 \\
R22 & 369.30 & 4.9900 & 0.1651 & 6.0580 & 0.2683 \\
R227ea & 374.90 & 2.9250 & 0.2861 & 3.4950 & 0.2685 \\
R23 & 299.29 & 4.8320 & 0.1330 & 7.5199 & 0.2582 \\
R236ea & 412.44 & 3.5020 & 0.2701 & 3.7030 & 0.2758 \\
R236fa & 398.07 & 3.2000 & 0.2758 & 3.6259 & 0.2667 \\
R245ca & 447.57 & 3.9250 & 0.2560 & 3.9059 & 0.2701 \\
R245fa & 427.16 & 3.6510 & 0.2597 & 3.8500 & 0.2670 \\
R32 & 351.26 & 5.7820 & 0.1227 & 8.1500 & 0.2429 \\
R365mfc & 460.00 & 3.2660 & 0.3125 & 3.2000 & 0.2669 \\
R41 & 317.28 & 5.8970 & 0.1075 & 9.2997 & 0.2404 \\
RC318 & 388.38 & 2.7775 & 0.3226 & 3.0994 & 0.2775 \\
CF $I$ & 396.44 & 3.9530 & 0.2257 & 4.4307 & 0.2707 \\
\hline \hline
\end{tabular}


Table 3: Acentric factors $\omega$, rectilinear diameters $r_{d}$, triple point temperatures $T_{t}$, and lowest temperatures for the VLE data used in the optimization, $T_{0}$. The last column is the reference of the corresponding Span-Wagner Eos (a: unpublished or preliminary results). Part A.

\begin{tabular}{lcccccc}
\hline \hline Compound & $\omega$ & $r_{d}$ & $T_{t}$ & $T_{0}$ & $T_{0}^{\text {red }}$ & Ref. \\
\hline methane & 0.0114 & 0.7389 & 90.694 & 100 & 0.52 & {$[38]$} \\
ethane & 0.0995 & 0.8243 & 90.368 & 100 & 0.33 & {$[39]$} \\
propane & 0.1521 & 0.8617 & 85.525 & 90 & 0.24 & {$[40]$} \\
n-butane & 0.2010 & 0.8965 & 134.9 & 140 & 0.33 & {$[41]$} \\
n-pentane & 0.2510 & 0.9254 & 143.47 & 150 & 0.32 & {$[42]$} \\
n-hexane & 0.2990 & 0.9746 & 177.83 & 180 & 0.35 & {$[42]$} \\
n-heptane & 0.3490 & 1.0165 & 182.55 & 190 & 0.35 & {$[42]$} \\
n-octane & 0.3930 & 1.0096 & 216.37 & 220 & 0.39 & {$[42]$} \\
n-nonane & 0.4433 & 1.0656 & 219.7 & 220 & 0.37 & {$[43]$} \\
n-decane & 0.4884 & 1.0705 & 243.5 & 250 & 0.40 & {$[43]$} \\
benzene & 0.2110 & 0.9263 & 278.67 & 280 & 0.50 & {$[44]$} \\
toluene & 0.2657 & 0.9572 & 178 & 180 & 0.30 & {$[43]$} \\
cyclopropane & 0.1305 & 0.8973 & 273 & 280 & 0.70 & {$[45]$} \\
cyclopentane & 0.1950 & 0.9004 & 179.72 & 180 & 0.35 & $\mathrm{a}$ \\
cyclohexane & 0.2093 & 0.9086 & 279.47 & 280 & 0.51 & {$[46]$} \\
methylcyclohexane & 0.2300 & 0.9097 & 146.7 & 150 & 0.26 & $\mathrm{a}$ \\
propylcyclohexane & 0.3300 & 0.9832 & 178.2 & 180 & 0.29 & $\mathrm{a}$ \\
isobutane & 0.1840 & 0.8905 & 113.73 & 120 & 0.29 & {$[41]$} \\
isopentane & 0.2274 & 0.8874 & 112.65 & 120 & 0.26 & {$[43]$} \\
isohexane & 0.2797 & 0.9552 & 119.6 & 120 & 0.24 & {$[43]$} \\
neopentane & 0.1961 & 0.8147 & 256.6 & 260 & 0.60 & {$[43]$} \\
ethene & 0.0866 & 0.8353 & 103.99 & 110 & 0.39 & {$[47]$} \\
propene & 0.1460 & 0.8863 & 87.953 & 90 & 0.25 & $\mathrm{a}$ \\
1-butene & 0.1920 & 0.9096 & 87.8 & 90 & 0.21 & {$[48]$} \\
cis-2-butene & 0.2020 & 0.9527 & 134.3 & 140 & 0.32 & {$[48]$} \\
trans-2-butene & 0.2100 & 0.9188 & 167.6 & 170 & 0.40 & {$[48]$} \\
isobutene & 0.1930 & 0.9351 & 132.4 & 140 & 0.33 & {$[48]$} \\
sulfurhexafluoride & 0.2100 & 0.8555 & 223.56 & 230 & 0.72 & {$[49]$} \\
fluorine & 0.0449 & 0.6922 & 53.481 & 60 & 0.42 & {$[50]$} \\
oxygen & 0.0222 & 0.7678 & 54.361 & 60 & 0.39 & {$[51]$} \\
nitrogen & 0.0372 & 0.7662 & 63.151 & 70 & 0.55 & {$[52]$} \\
carbonmonoxide & 0.0497 & 0.8184 & 68.16 & 70 & 0.53 & {$[43]$} \\
carbondioxide & 0.2239 & 0.9539 & 216.59 & 220 & 0.72 & {$[53]$} \\
argon & -0.0022 & 0.7301 & 83.806 & 90 & 0.60 & {$[54]$} \\
sulfurdioxide & 0.2557 & 1.0044 & 197.7 & 200 & 0.46 & {$[43]$} \\
nitrousoxide & 0.1613 & 0.9013 & 182.33 & 190 & 0.61 & {$[43]$} \\
\hline \hline
\end{tabular}


Table 4: Acentric factors $\omega$, rectilinear diameters $r_{d}$, triple point temperatures $T_{t}$, and lowest temperatures for the VLE data used in the optimization, $T_{0}$. The last column is the reference of the corresponding Span-Wagner Eos (a: unpublished or preliminary results). Part B - halogenated compounds.

\begin{tabular}{|c|c|c|c|c|c|c|}
\hline Compound & $\omega$ & $r_{d}$ & $\overline{T_{t}}$ & $\overline{T_{0}}$ & $T_{0}^{\text {red }}$ & Ref. \\
\hline perfluorobutane & 0.3740 & 1.0103 & 189 & 190 & 0.49 & {$[55]$} \\
\hline perfluoropentane & 0.4230 & 1.1077 & 148.36 & 200 & 0.48 & {$[55]$} \\
\hline R11 & 0.1888 & 0.9118 & 162.68 & 170 & 0.36 & {$[56]$} \\
\hline $\mathrm{R} 113$ & 0.2525 & 1.0216 & 236.93 & 270 & 0.55 & {$[57]$} \\
\hline R114 & 0.2523 & 0.9299 & 273.15 & 280 & 0.67 & {$[58]$} \\
\hline $\mathrm{R} 115$ & 0.2500 & 0.8225 & 173.75 & 180 & 0.51 & $\mathrm{a}$ \\
\hline $\mathrm{R} 116$ & 0.2566 & 0.9443 & 173.1 & 180 & 0.61 & {$[43]$} \\
\hline $\mathrm{R} 12$ & 0.1795 & 0.8849 & 116.1 & 120 & 0.31 & {$[57]$} \\
\hline $\mathrm{R} 123$ & 0.2819 & 0.9582 & 166 & 170 & 0.37 & {$[59]$} \\
\hline R1234yf & 0.2760 & 0.9890 & 220 & 230 & 0.63 & {$[60]$} \\
\hline R1234ze & 0.3130 & 0.9621 & 168.62 & 170 & 0.44 & {$[61]$} \\
\hline $\mathrm{R} 124$ & 0.2881 & 0.9399 & 120 & 130 & 0.33 & {$[62]$} \\
\hline $\mathrm{R} 125$ & 0.3052 & 0.9655 & 172.52 & 180 & 0.53 & {$[63]$} \\
\hline $\mathrm{R} 13$ & 0.1723 & 0.8622 & 92 & 100 & 0.33 & {$[64]$} \\
\hline R134a & 0.3268 & 1.0147 & 169.85 & 170 & 0.45 & {$[65]$} \\
\hline $\mathrm{R} 14$ & 0.1785 & 0.8068 & 120 & 130 & 0.57 & {$[58]$} \\
\hline R141b & 0.2195 & 0.9333 & 169.68 & 170 & 0.36 & {$[43]$} \\
\hline $\mathrm{R} 142 \mathrm{~b}$ & 0.2321 & 0.9599 & 142.72 & 150 & 0.37 & {$[43]$} \\
\hline R143a & 0.2615 & 1.0216 & 161.34 & 170 & 0.49 & {$[66]$} \\
\hline R152a & 0.2752 & 1.0364 & 154.56 & 160 & 0.41 & {$[67]$} \\
\hline R161 & 0.2170 & 0.9023 & 130 & 140 & 0.37 & a \\
\hline R21 & 0.2061 & 0.9034 & 200 & 210 & 0.47 & {$[58]$} \\
\hline $\mathrm{R} 218$ & 0.3172 & 0.9411 & 125.45 & 130 & 0.38 & {$[43]$} \\
\hline $\mathrm{R} 22$ & 0.2208 & 0.9366 & 115.73 & 120 & 0.32 & {$[68]$} \\
\hline R227ea & 0.3570 & 0.9532 & 146.35 & 150 & 0.40 & a \\
\hline $\mathrm{R} 23$ & 0.2630 & 1.0186 & 118.02 & 120 & 0.40 & [69] \\
\hline R236ea & 0.3794 & 1.0016 & 242 & 250 & 0.61 & {$[55]$} \\
\hline R236fa & 0.3772 & 1.0140 & 179.52 & 180 & 0.45 & {$[70]$} \\
\hline R245ca & 0.3536 & 0.9713 & 200 & 210 & 0.47 & {$[55]$} \\
\hline R245fa & 0.3776 & 0.9987 & 171.05 & 210 & 0.49 & {$[43]$} \\
\hline R32 & 0.2769 & 1.1223 & 136.34 & 140 & 0.40 & {$[71]$} \\
\hline $\mathrm{R} 365 \mathrm{mfc}$ & 0.3800 & 0.9430 & 239 & 240 & 0.52 & $\mathrm{a}$ \\
\hline R41 & 0.2004 & 1.0057 & 129.82 & 130 & 0.41 & {$[43]$} \\
\hline RC318 & 0.3553 & 0.9935 & 233.35 & 240 & 0.62 & {$[58]$} \\
\hline$C F_{3} I$ & 0.1800 & 0.8387 & 120 & 130 & 0.33 & $\mathrm{a}$ \\
\hline
\end{tabular}


Table 5: Systematic names of studied halogenated refrigerants.

\begin{tabular}{lll}
\hline \hline Refprop abbreviation & RCN abbreviation & Systematic name \\
\hline R11 & CFC11 & trichlorofluoromethane \\
R113 & CFC113 & 1,1,2-trichloro-1,2,2-trifluoroethane \\
R114 & CFC114 & 1,2-dichloro-1,1,2,2-tetrafluoroethane \\
R115 & CFC115 & chloropentafluoroethane \\
R116 & FC116 & hexafluoroethane \\
R12 & CFC12 & dichlorodifluoromethane \\
R123 & HCFC123 & 2,2 -dichloro-1,1,1-trifluoroethane \\
R1234yf & HFO1234yf & $2,3,3,3$-tetrafluoropropene \\
R1234ze & HFO1234ze & trans-1,3,3,3-tetrafluoropropene \\
R124 & HCFC124 & 1 -chloro-1,2,2,2-tetrafluoroethane \\
R125 & HFC125 & pentafluoroethane \\
R13 & CFC13 & chlorotrifluoromethane \\
R134a & HFC134a & $1,1,1,2$-tetrafluoroethane \\
R14 & FC14 & tetrafluoromethane \\
R141b & HFC141b & 1,1 -dichloro-1-fluoroethane \\
R142b & HCFC143b & 1 -chloro-1,1-difluoroethane \\
R143a & HFC143a & $1,1,1$-trifluoroethane \\
R152a & HFC152a & 1,1 -difluoroethane \\
R161 & HFC161 & fluoroethane \\
R21 & HCFC2 1 & dichlorofluoromethane \\
R218 & FC218 & octafluoropropane \\
R22 & HCFC22 & chlorodifluoromethane \\
R227ea & HFC227ea & $1,1,1,2,3,3,3$-heptafluoropropane \\
R23 & HFC23 & trifluoromethane \\
R236ea & HFC236ea & $1,1,1,2,3,3$-hexafluoropropane \\
R236fa & HFC236fa & $1,1,1,3,3,3$-hexafluoropropane \\
R245ca & HFC245ca & $1,1,2,2,3-$ pentafluoropropane \\
R245fa & HFC245fa & $1,1,1,3,3$-pentafluoropropane \\
R32 & HFC32 & difluoromethane \\
R365mfc & HFC365mfc & $1,1,1,3,3$-pentafluorobutane \\
R41 & HFC41 & fluoromethane \\
RC318 & FC318 & octafluorocyclobutane \\
\hline \hline & & \\
\hline
\end{tabular}


Table 6: Average absolute deviations in \% of vapor pressure/liquid density/vapor density/ equilibrium pressure ( $P V T$ data) for different models of parametrization. Part A.

\begin{tabular}{|c|c|c|c|}
\hline Name & $\begin{array}{c}\text { Model A } \\
\Delta P_{s} / \Delta \rho_{L} / \Delta \rho_{V} / \Delta P\end{array}$ & $\begin{array}{c}\text { Model B } \\
\Delta P_{s} / \Delta \rho_{L} / \Delta \rho_{V} / \Delta P\end{array}$ & $\begin{array}{c}\text { Model C } \\
\Delta P_{s} / \Delta \rho_{L} / \Delta \rho_{V} / \Delta P\end{array}$ \\
\hline methane & $1.3 / 2.8 / 3.0 / 0.8$ & $1.6 / 1.4 / 3.3 / 5.4$ & $1.5 / 1.9 / 3.2 / 18.2$ \\
\hline ethane & $1.2 / 1.3 / 2.1 / 0.6$ & $1.2 / 0.5 / 2.3 / 3.2$ & $1.2 / 0.8 / 2.2 / 9.8$ \\
\hline propane & $0.7 / 1.2 / 1.6 / 0.8$ & $2.9 / 0.8 / 3.8 / 3.1$ & $2.9 / 0.9 / 3.8 / 8.4$ \\
\hline n-butane & $0.8 / 1.5 / 1.8 / 0.8$ & 2.6/1.3/3.8/2.3 & $2.2 / 1.4 / 3.0 / 3.6$ \\
\hline n-pentane & $1.0 / 1.9 / 1.8 / 0.5$ & 2.9/2.2/3.7/1.9 & $2.9 / 2.2 / 3.7 / 2.1$ \\
\hline n-hexane & $0.6 / 2.3 / 1.4 / 0.6$ & $0.6 / 2.4 / 1.4 / 3.4$ & $0.6 / 2.3 / 1.4 / 3.8$ \\
\hline n-heptane & $1.2 / 2.5 / 1.9 / 0.4$ & $2.0 / 3.2 / 2.8 / 2.9$ & $2.1 / 2.9 / 2.9 / 3.3$ \\
\hline n-octane & $1.2 / 2.6 / 1.8 / 0.4$ & $1.7 / 3.6 / 2.7 / 3.0$ & $2.2 / 3.2 / 3.1 / 7.9$ \\
\hline n-nonane & $1.3 / 3.2 / 2.1 / 0.6$ & $6.2 / 3.2 / 8.9 / 2.5$ & $8.1 / 3.2 / 8.9 / 2.5$ \\
\hline decane & $1.0 / 3.5 / 1.5 / 0.4$ & $9.6 / 4.0 / 10.0 / 2.8$ & $10.1 / 3.6 / 10.7 / 36.6$ \\
\hline benzene & $0.8 / 1.3 / 1.9 / 0.6$ & $3.2 / 1.3 / 4.6 / 1.7$ & $3.2 / 1.3 / 4.6 / 1.8$ \\
\hline toluene & $2.1 / 2.6 / 2.5 / 2.7$ & $4.8 / 2.7 / 5.0 / 1.4$ & $4.9 / 3.1 / 5.1 / 2.4$ \\
\hline cyclopropane & $0.6 / 1.5 / 2.4 / 0.5$ & $1.7 / 1.2 / 3.6 / 1.7$ & $1.7 / 5.2 / 3.6 / 2.6$ \\
\hline cyclopentane & $0.8 / 1.1 / 1.1 / 2.5$ & $2.7 / 1.5 / 2.6 / 1.2$ & $2.6 / 1.3 / 2.6 / 2.2$ \\
\hline cyclohexane & $0.6 / 1.1 / 1.2 / 0.6$ & $2.4 / 1.1 / 2.0 / 1.7$ & $2.4 / 1.2 / 1.9 / 1.8$ \\
\hline methylcyclohexane & $1.5 / 1.6 / 2.0 / 0.8$ & $8.2 / 2.1 / 8.9 / 2.2$ & $8.2 / 2.0 / 8.9 / 2.3$ \\
\hline propylcyclohexane & $2.0 / 2.4 / 2.6 / 0.3$ & 1.7/3.3/2.1/1.4 & $1.7 / 3.0 / 2.1 / 2.7$ \\
\hline isobutane & $1.2 / 1.5 / 2.1 / 0.6$ & $4.5 / 1.5 / 5.4 / 1.8$ & $4.5 / 1.4 / 5.4 / 2.7$ \\
\hline isopentane & $0.9 / 1.5 / 2.0 / 0.6$ & $3.5 / 1.5 / 4.6 / 1.8$ & $3.5 / 1.5 / 4.6 / 2.3$ \\
\hline isohexane & $0.9 / 1.6 / 1.4 / 0.4$ & $0.8 / 1.7 / 1.4 / 1.5$ & $0.9 / 1.7 / 1.4 / 1.7$ \\
\hline neopentane & $0.5 / 0.9 / 2.3 / 0.6$ & $2.0 / 0.7 / 4.3 / 1.2$ & $2.0 / 0.7 / 4.3 / 1.2$ \\
\hline ethene & $0.6 / 1.5 / 1.8 / 0.5$ & $1.8 / 1.5 / 3.1 / 1.4$ & $1.8 / 0.9 / 3.1 / 1.9$ \\
\hline propene & $0.8 / 1.3 / 1.9 / 0.6$ & 4.0/1.3/5.1/1.8 & $4.0 / 1.1 / 5.1 / 2.3$ \\
\hline 1-butene & $1.1 / 1.6 / 1.9 / 0.4$ & $3.8 / 2.2 / 4.0 / 1.1$ & $4.8 / 1.6 / 5.5 / 1.7$ \\
\hline cis-2-butene & $1.8 / 1.8 / 2.6 / 0.6$ & $5.2 / 1.8 / 5.6 / 1.5$ & $5.3 / 1.8 / 5.7 / 1.9$ \\
\hline trans-2-butene & $1.3 / 1.5 / 1.9 / 0.4$ & 2.5/1.6/3.3/1.8 & $2.6 / 1.8 / 3.4 / 2.9$ \\
\hline isobutene & $0.4 / 1.4 / 2.1 / 0.8$ & $3.0 / 1.5 / 3.2 / 1.3$ & $3.1 / 1.4 / 3.3 / 2.2$ \\
\hline sulfurhexafluoride & $0.7 / 1.6 / 2.6 / 0.8$ & $2.0 / 1.2 / 4.5 / 2.2$ & $1.9 / 1.4 / 4.5 / 2.2$ \\
\hline fluorine & $1.3 / 2.4 / 1.2 / 0.9$ & $2.7 / 2.2 / 4.2 / 2.0$ & $2.7 / 2.3 / 4.2 / 2.0$ \\
\hline oxygene & $1.4 / 2.7 / 2.4 / 0.5$ & 2.9/2.9/3.9/1.5 & 2.9/2.6/3.9/2.0 \\
\hline nitrogene & $0.9 / 2.8 / 2.2 / 0.9$ & $1.1 / 3.5 / 2.1 / 1.2$ & $1.0 / 2.8 / 2.2 / 1.7$ \\
\hline carbonmonooxide & $0.6 / 2.4 / 2.1 / 0.9$ & $0.9 / 2.1 / 2.3 / 2.0$ & $0.9 / 2.9 / 2.2 / 2.7$ \\
\hline carbondioxide & $0.4 / 1.5 / 2.1 / 0.6$ & $0.7 / 1.4 / 2.7 / 1.9$ & $0.7 / 1.6 / 2.7 / 2.1$ \\
\hline argon & $0.9 / 2.8 / 2.6 / 0.6$ & $1.1 / 2.9 / 2.8 / 1.6$ & $1.1 / 2.3 / 2.8 / 2.5$ \\
\hline sulfurdioxide & $0.5 / 1.8 / 1.6 / 0.5$ & $1.7 / 1.9 / 2.1 / 1.3$ & $1.7 / 1.9 / 2.1 / 1.3$ \\
\hline nitrousoxide & $0.4 / 1.1 / 1.7 / 0.5$ & 2.0/1.0/3.4/1.9 & $2.0 / 0.8 / 3.4 / 2.2$ \\
\hline
\end{tabular}


Table 7: Average absolute deviations in \% of vapor pressure/liquid density/vapor density/ equilibrium pressure ( $P V T$ data) for different models of parametrization. Part $\mathrm{B}$ - halogenated compounds.

\begin{tabular}{|c|c|c|c|}
\hline Compound & $\begin{array}{c}\text { Model A } \\
\Delta P_{s} / \Delta \rho_{L} / \Delta \rho_{V} / \Delta P\end{array}$ & $\begin{array}{c}\text { Model B } \\
\Delta P_{s} / \Delta \rho_{L} / \Delta \rho_{V} / \Delta P\end{array}$ & $\begin{array}{c}\text { Model C } \\
\Delta P_{s} / \Delta \rho_{L} / \Delta \rho_{V} / \Delta P\end{array}$ \\
\hline perfluorobutane & $0.8 / 2.9 / 1.2 / 1.4$ & $7.7 / 2.6 / 8.3 / 2.3$ & $7.6 / 1.8 / 8.2 / 3.1$ \\
\hline perfluoropentane & $2.1 / 1.8 / 3.2 / 1.4$ & $2.3 / 1.8 / 3.6 / 2.1$ & $2.4 / 3.6 / 3.7 / 11.5$ \\
\hline $\mathrm{R} 11$ & $0.9 / 1.1 / 1.8 / 0.6$ & $2.2 / 1.1 / 3.0 / 1.6$ & $2.2 / 1.3 / 3.0 / 2.1$ \\
\hline $\mathrm{R} 113$ & $0.6 / 1.0 / 2.1 / 0.8$ & $1.1 / 1.5 / 2.4 / 1.6$ & $1.0 / 1.6 / 2.4 / 2.5$ \\
\hline $\mathrm{R} 114$ & $0.7 / 1.0 / 2.5 / 0.8$ & $0.7 / 0.8 / 2.9 / 1.7$ & $0.6 / 1.4 / 2.9 / 2.5$ \\
\hline $\mathrm{R} 115$ & $0.9 / 0.9 / 3.2 / 0.9$ & $1.1 / 1.8 / 2.9 / 1.9$ & $1.7 / 1.2 / 4.1 / 3.7$ \\
\hline $\mathrm{R} 116$ & $0.8 / 1.3 / 2.6 / 0.7$ & $1.0 / 1.0 / 2.6 / 2.3$ & $1.0 / 2.4 / 2.7 / 4.1$ \\
\hline $\mathrm{R} 12$ & $1.4 / 1.5 / 2.4 / 0.6$ & $4.2 / 1.4 / 5.2 / 1.9$ & $4.2 / 1.5 / 5.2 / 1.8$ \\
\hline R123 & $0.8 / 1.5 / 2.0 / 0.6$ & $1.5 / 1.6 / 2.5 / 2.1$ & $1.6 / 1.6 / 2.5 / 2.3$ \\
\hline R1234yf & $0.8 / 1.0 / 1.9 / 0.5$ & $1.2 / 1.1 / 2.4 / 2.2$ & $1.2 / 1.1 / 2.4 / 2.1$ \\
\hline R1234ze & $0.8 / 1.5 / 1.7 / 0.5$ & $1.3 / 1.6 / 2.7 / 2.1$ & $1.3 / 1.6 / 2.6 / 2.3$ \\
\hline $\mathrm{R} 124$ & $1.6 / 2.1 / 2.5 / 0.6$ & $2.6 / 2.2 / 3.4 / 2.4$ & $2.6 / 2.2 / 3.4 / 2.5$ \\
\hline $\mathrm{R} 125$ & $0.4 / 1.2 / 1.5 / 0.6$ & $0.6 / 1.2 / 1.9 / 2.2$ & $0.6 / 1.3 / 1.9 / 2.3$ \\
\hline $\mathrm{R} 13$ & $1.3 / 1.3 / 2.7 / 0.7$ & $4.8 / 1.3 / 6.1 / 1.9$ & $4.8 / 1.3 / 6.1 / 1.9$ \\
\hline $\mathrm{R} 134 \mathrm{a}$ & $0.5 / 2.1 / 1.4 / 0.4$ & $0.5 / 2.4 / 1.7 / 2.2$ & $0.5 / 2.4 / 1.6 / 2.6$ \\
\hline $\mathrm{R} 14$ & $0.8 / 2.0 / 2.5 / 0.9$ & $1.2 / 1.8 / 3.4 / 2.3$ & $1.2 / 2.1 / 3.4 / 2.4$ \\
\hline $\mathrm{R} 141 \mathrm{~b}$ & $1.0 / 1.9 / 2.1 / 0.5$ & $6.7 / 1.8 / 8.1 / 1.7$ & $6.7 / 1.8 / 8.1 / 1.6$ \\
\hline $\mathrm{R} 142 \mathrm{~b}$ & $2.1 / 1.6 / 3.4 / 0.7$ & $4.3 / 2.0 / 5.2 / 1.8$ & $4.4 / 2.1 / 5.3 / 2.8$ \\
\hline R143a & $1.1 / 2.0 / 1.5 / 0.6$ & $3.0 / 2.4 / 3.6 / 2.7$ & $3.3 / 3.0 / 3.8 / 4.7$ \\
\hline R152a & $1.2 / 2.6 / 1.4 / 0.5$ & $3.2 / 3.1 / 3.7 / 2.1$ & $3.7 / 4.1 / 4.2 / 5.0$ \\
\hline R161 & $1.3 / 4.7 / 1.8 / 2.0$ & $3.3 / 7.8 / 3.3 / 2.7$ & $7.0 / 6.0 / 7.2 / 20.2$ \\
\hline $\mathrm{R} 21$ & $0.6 / 1.3 / 2.2 / 0.6$ & $3.5 / 1.3 / 4.8 / 1.4$ & $3.6 / 1.2 / 4.9 / 2.8$ \\
\hline $\mathrm{R} 218$ & $0.8 / 1.4 / 1.8 / 1.2$ & $2.9 / 1.6 / 4.4 / 0.9$ & $3.5 / 2.2 / 4.4 / 3.2$ \\
\hline $\mathrm{R} 22$ & $1.3 / 2.1 / 2.1 / 0.5$ & $5.6 / 2.4 / 6.2 / 2.0$ & $5.7 / 2.5 / 6.3 / 2.4$ \\
\hline R227ea & $0.9 / 1.7 / 2.1 / 0.6$ & $3.1 / 1.7 / 4.2 / 2.5$ & $3.1 / 1.8 / 4.3 / 3.1$ \\
\hline $\mathrm{R} 23$ & $1.2 / 2.5 / 0.8 / 0.4$ & $2.6 / 2.9 / 2.6 / 2.4$ & $2.9 / 3.7 / 2.9 / 3.9$ \\
\hline R236ea & $1.4 / 2.4 / 3.6 / 2.0$ & $4.0 / 2.5 / 6.8 / 1.8$ & $4.0 / 3.1 / 6.8 / 2.9$ \\
\hline R236fa & $0.8 / 1.9 / 1.1 / 0.3$ & $3.4 / 2.0 / 3.8 / 1.5$ & $3.6 / 2.4 / 4.0 / 3.7$ \\
\hline $\mathrm{R} 245 \mathrm{ca}$ & $0.8 / 1.7 / 0.9 / 0.2$ & $3.7 / 1.9 / 4.5 / 1.9$ & $3.8 / 2.1 / 4.6 / 2.4$ \\
\hline $\mathrm{R} 245 \mathrm{fa}$ & $1.1 / 1.8 / 2.4 / 0.8$ & $3.4 / 2.0 / 4.7 / 4.3$ & $3.6 / 2.0 / 4.9 / 9.7$ \\
\hline $\mathrm{R} 32$ & $2.2 / 3.2 / 2.1 / 0.6$ & $3.4 / 3.8 / 3.3 / 2.6$ & $4.0 / 4.7 / 3.8 / 3.7$ \\
\hline $\mathrm{R} 365 \mathrm{mfc}$ & $1.5 / 1.2 / 2.6 / 0.6$ & $4.3 / 1.3 / 5.7 / 2.4$ & $4.3 / 1.8 / 5.8 / 4.1$ \\
\hline $\mathrm{R} 41$ & $2.7 / 2.9 / 1.8 / 0.3$ & $6.6 / 3.8 / 6.4 / 2.3$ & $7.3 / 6.4 / 7.1 / 5.4$ \\
\hline RC318 & $0.6 / 0.8 / 2.3 / 1.2$ & $2.8 / 1.8 / 3.8 / 1.4$ & $2.7 / 3.2 / 3.8 / 6.5$ \\
\hline$C F_{3} I$ & $2.6 / 1.3 / 3.2 / 0.5$ & $2.9 / 1.4 / 3.9 / 1.7$ & $2.9 / 1.4 / 3.9 / 1.8$ \\
\hline
\end{tabular}




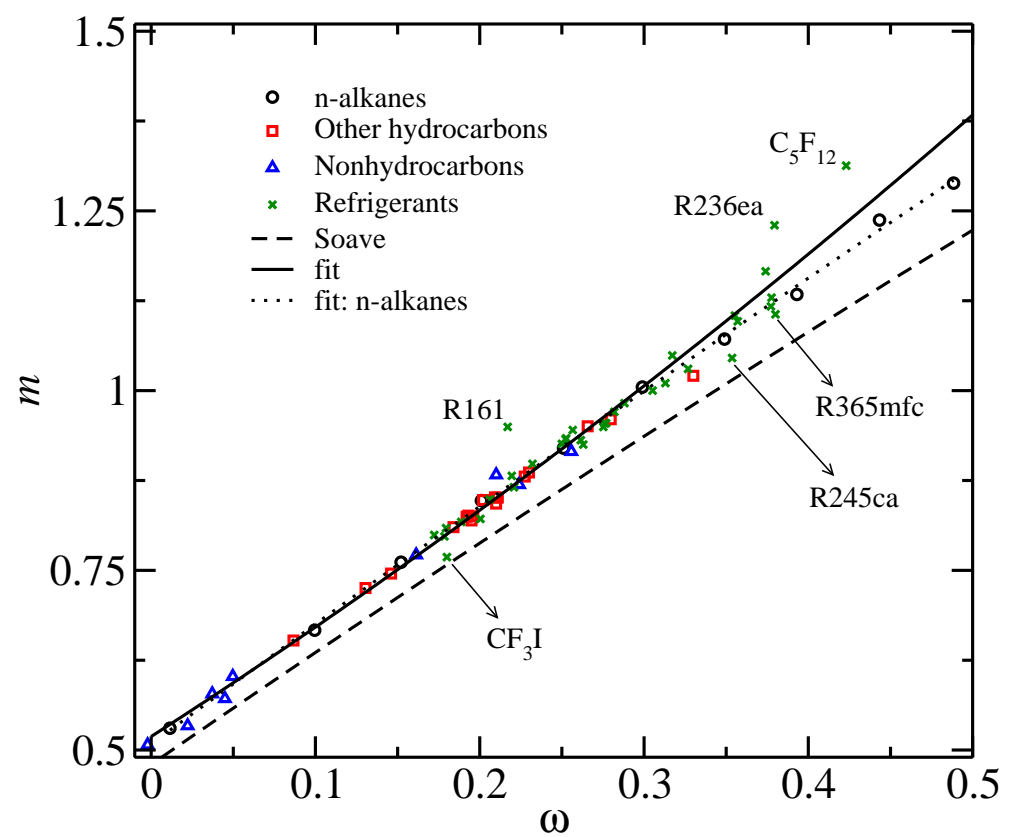

Figure 1: Dependence of the parameter $m$ on the acentric factor. The dashed line shows the correlation of Soave for classical SRK EoS [26]. The symbols correspond to the values of $m$ obtained from the optimization of 4 parameters of crossover SRK EoS (Model A). The solid- and dotted line- represent two different quadratic correlations of these points. 


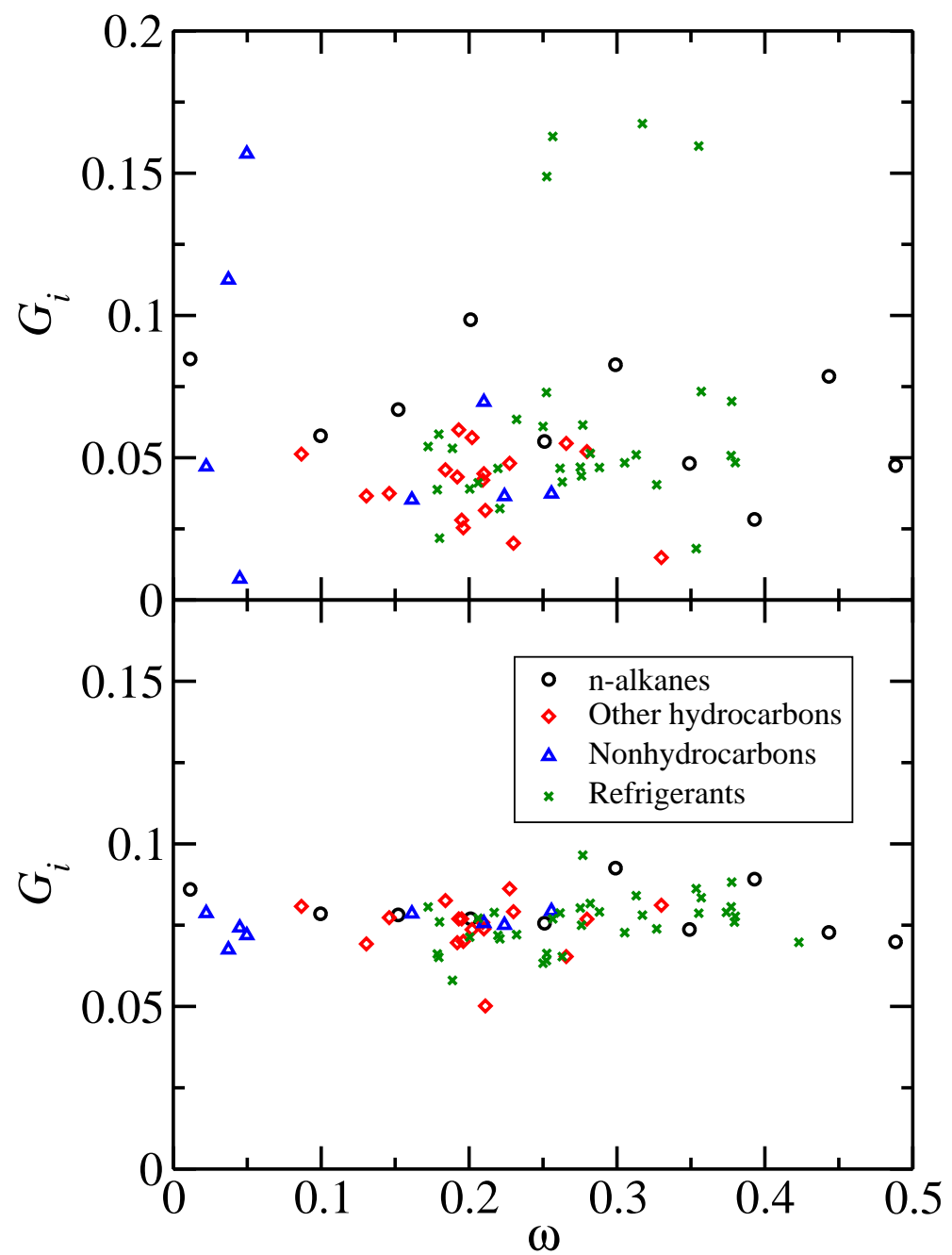

Figure 2: Ginzburg number $G_{i}$ obtained by simultaneous optimization of 4 parameters (Model A) as a function of the acentric factor (upper part). The results for Model B are shown in the lower part. 


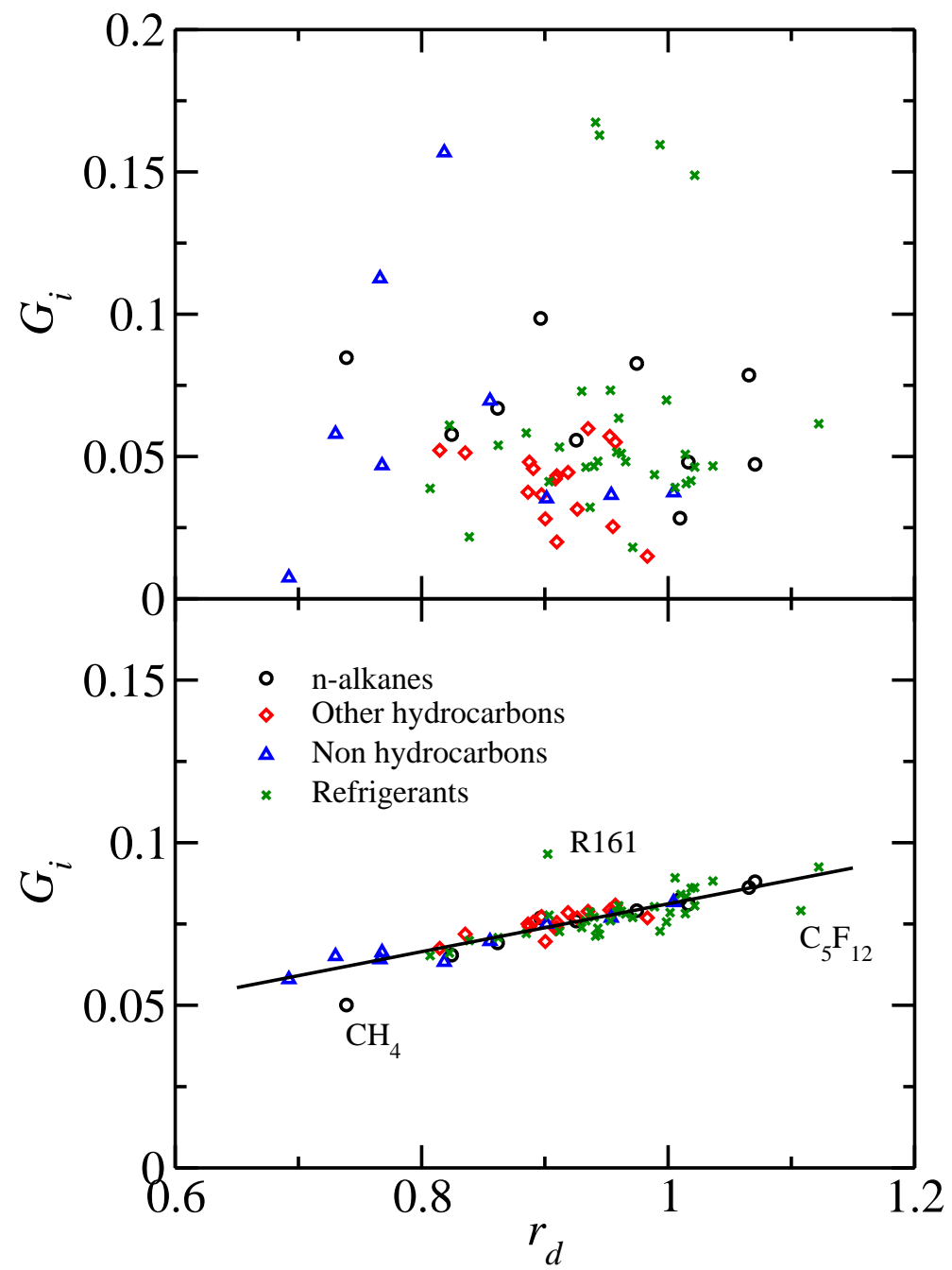

Figure 3: The same as in Figure 2 plotted vs. rectilinear diameter $r_{d}$. 


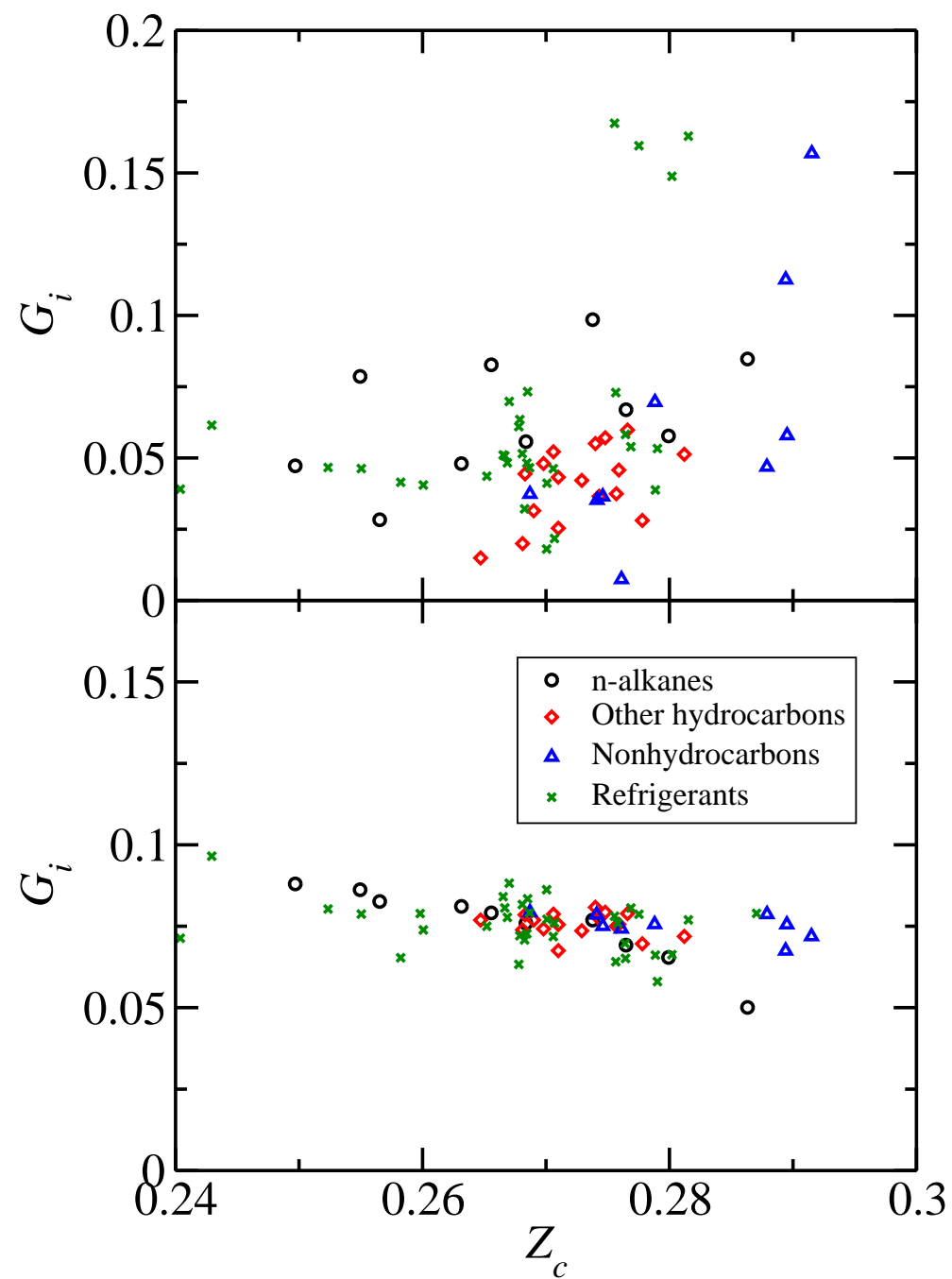

Figure 4: The same as in Figure 2 plotted vs. critical compression factor $Z_{c}$. 


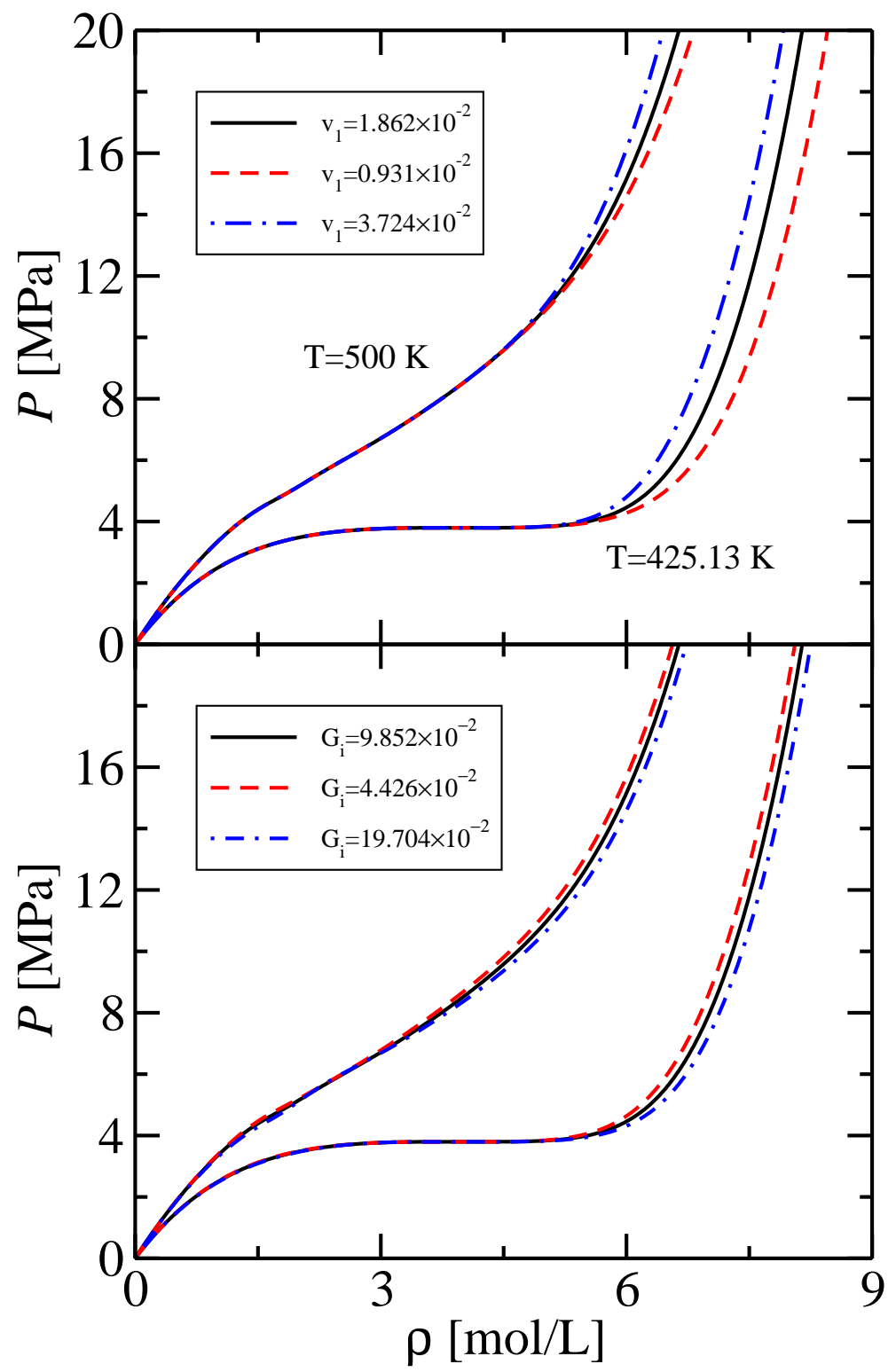

Figure 5: Influence of parameter $v_{1}$ (upper part) and of parameter $G_{i}$ (lower part) on the isotherms at $T=425.13 \mathrm{~K}$ and $T=500 \mathrm{~K}$ for n-butane. The solid black lines correspond to the optimal parameters of Model A $G_{i}=9.852 \times 10^{-2}, v_{1}=1.862 \times 10^{-2}$ and $d_{1}=-2.851$. The red dashed and blue dash-dotted to taking the respective parameter equal to one half or twice of the optimal value. 


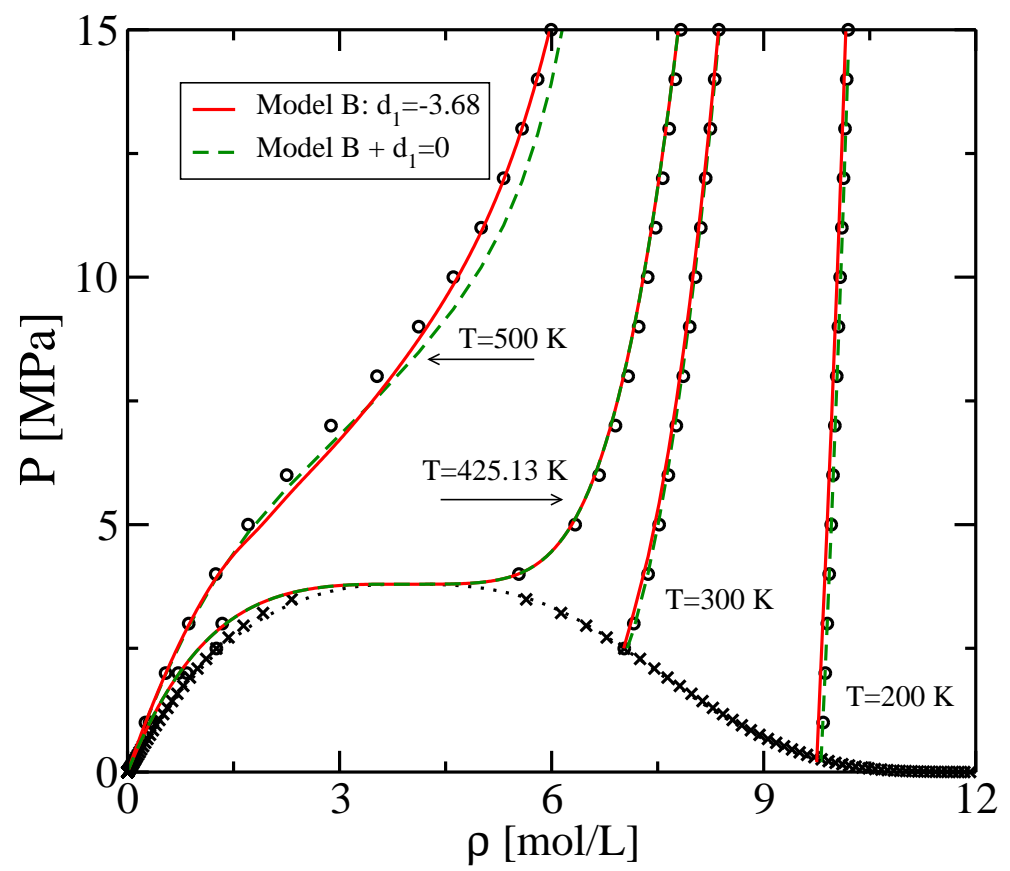

Figure 6: Isotherms for n-butane calculated with full Model B, with $d_{1}=$ -3.68 (solid red lines) and with parameter $d_{1}$ set to zero (green dashed lines). The symbols denote the Refprop data [33]. 


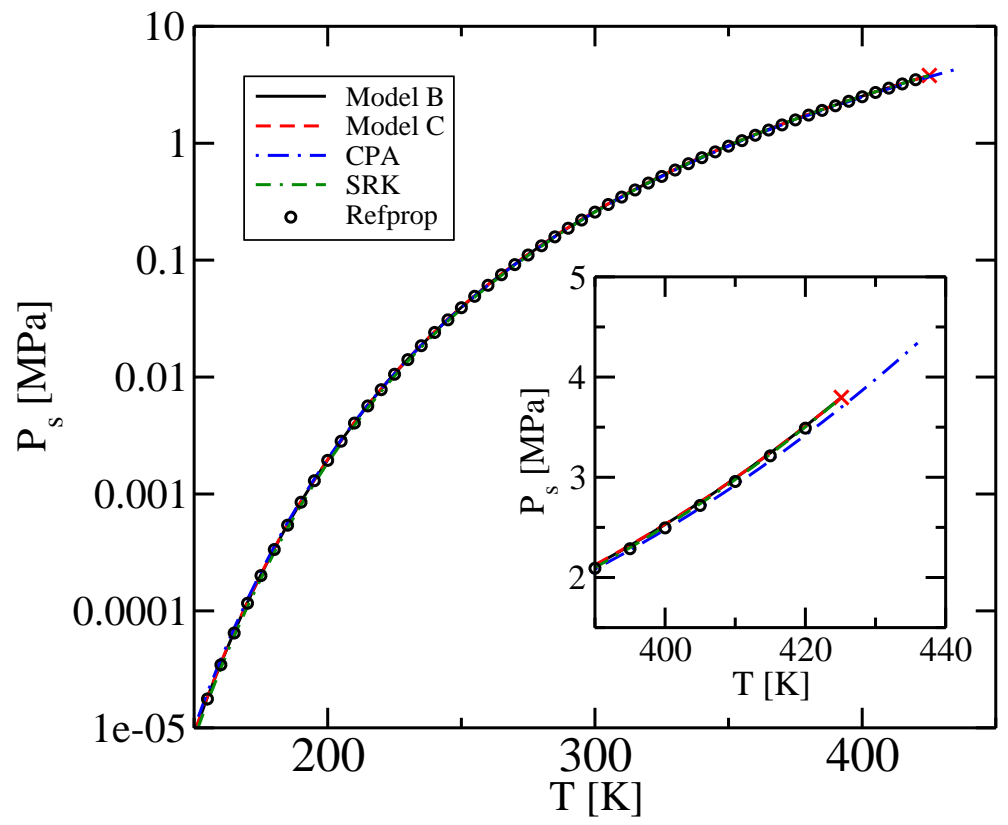

Figure 7: Saturated pressure for butane. The models B (solid black) and C (dashed red) of this work are compared with the CPA (blue dash-dotted) and SRK (green double-dash-dotted line) EoS's. Symbols are the Refprop data [33]. 


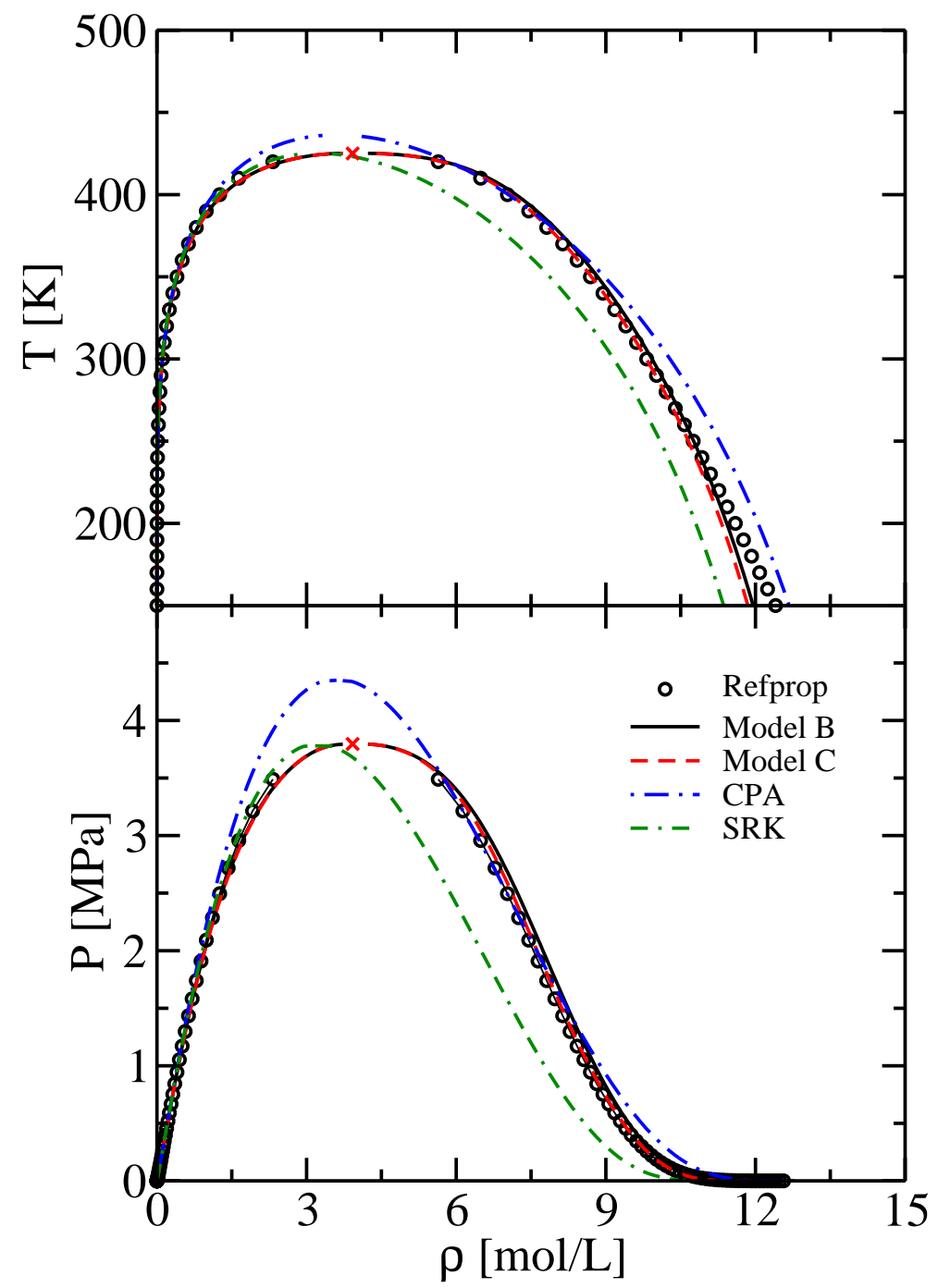

Figure 8: Phase diagram for n-butane according to models B (solid black) and $\mathrm{C}$ (dashed red) of this work and CPA (blue dash-dotted) and SRK (green double-dash-dotted line) EoS's. Symbols are the Refprop data [33]. 


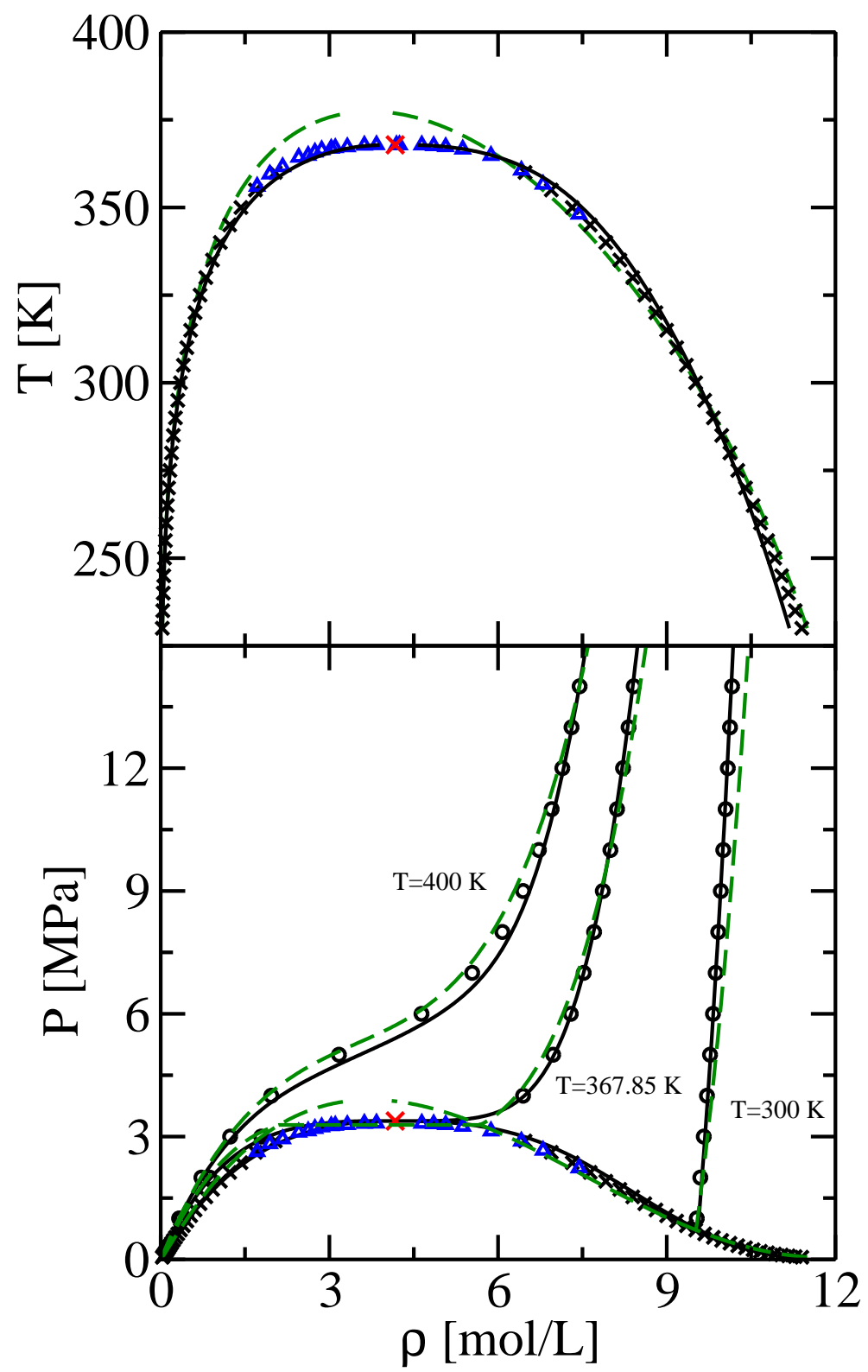

Figure 9: Phase diagram for 2,3,3,3,-tetrafluoropropene (R1234yf). Model C of the crossover SRK EoS (solid black lines) is compared with classical SRK EoS parametrized in the CPA way (green dash-dotted lines). Black symbols are the Refprop data [33], blue open triangles represent the experimental coexistence densities of [34]. 


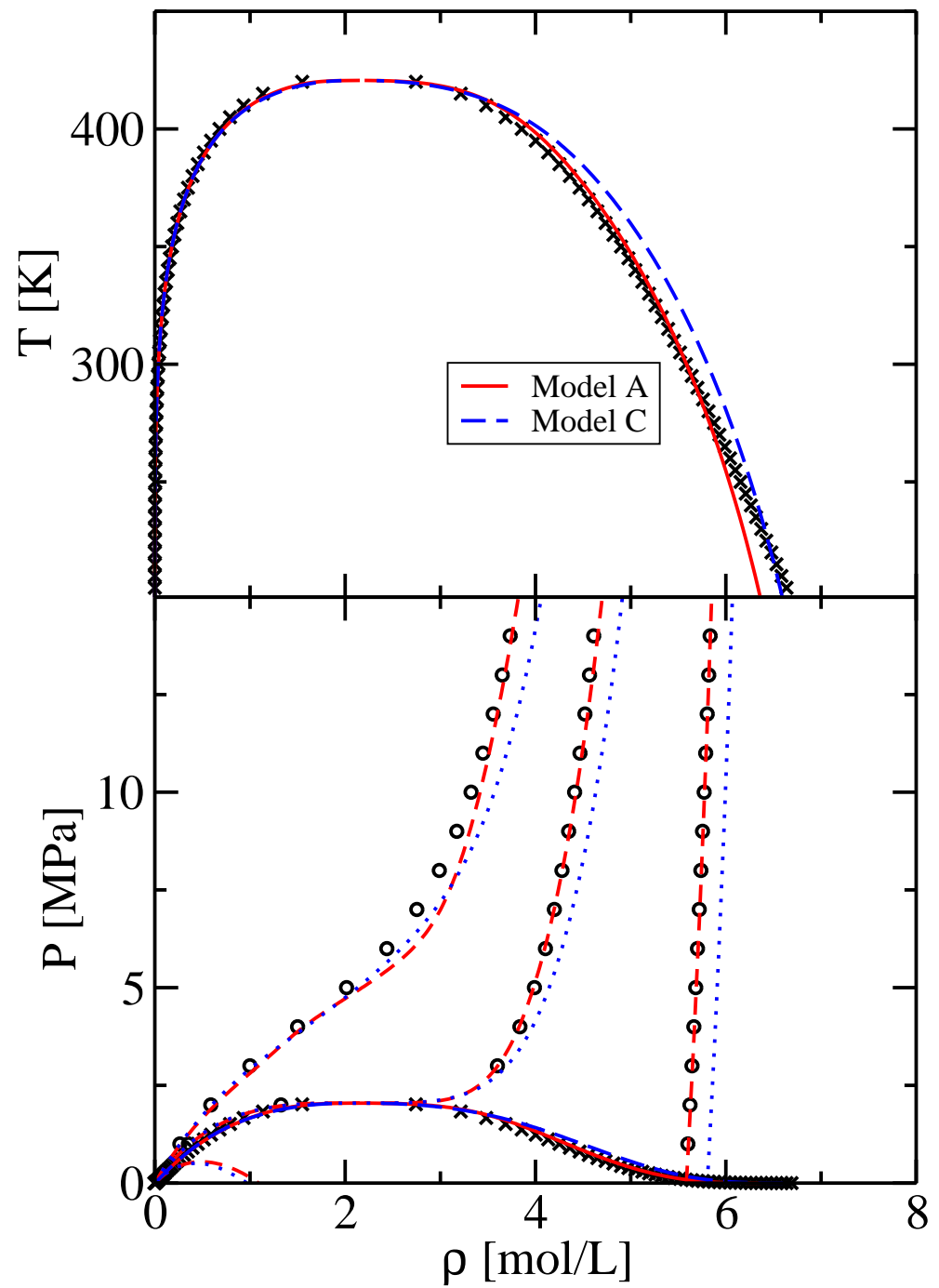

Figure 10: Phase diagram for perfluoropentane. Model $\mathrm{C}$ of the crossover SRK EoS (dashed blue lines) is compared with Model A (solid red lines). Symbols are the Refprop data [33]. 


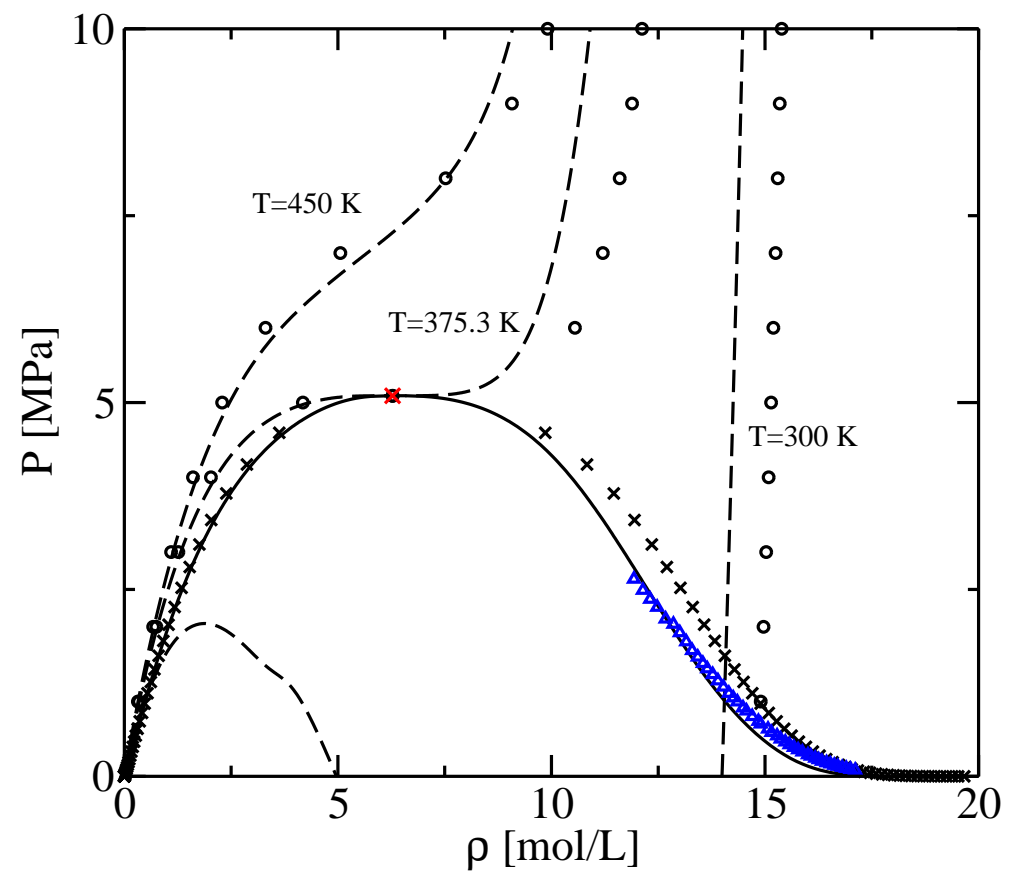

Figure 11: Coexistence curve (solid line) and three isotherms (dashed lines) for R161 calculated by Model C of the crossover SRK EoS. The black symbols denote the Refprop data while the blue triangles are experimental liquid densities of Han et al. [35]. 


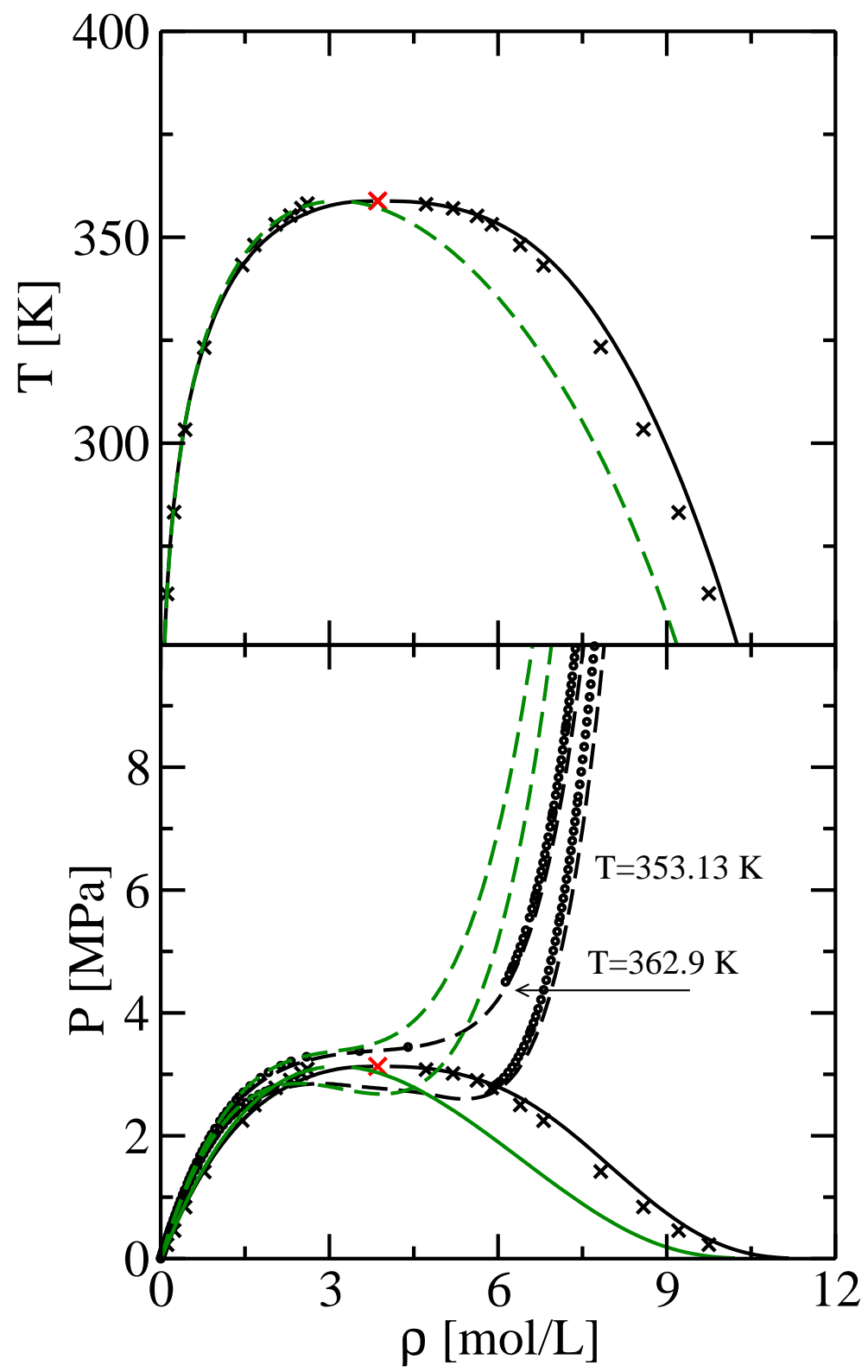

Figure 12: Phase diagram for hexafluoropropene (R1216). Model C of crossover SRK EoS (solid black lines) is compared with classical SRK EoS with parameters adjusted to reproduce the critical temperature and pressure (green dashed lines). Symbols are the experimental data [36]. 


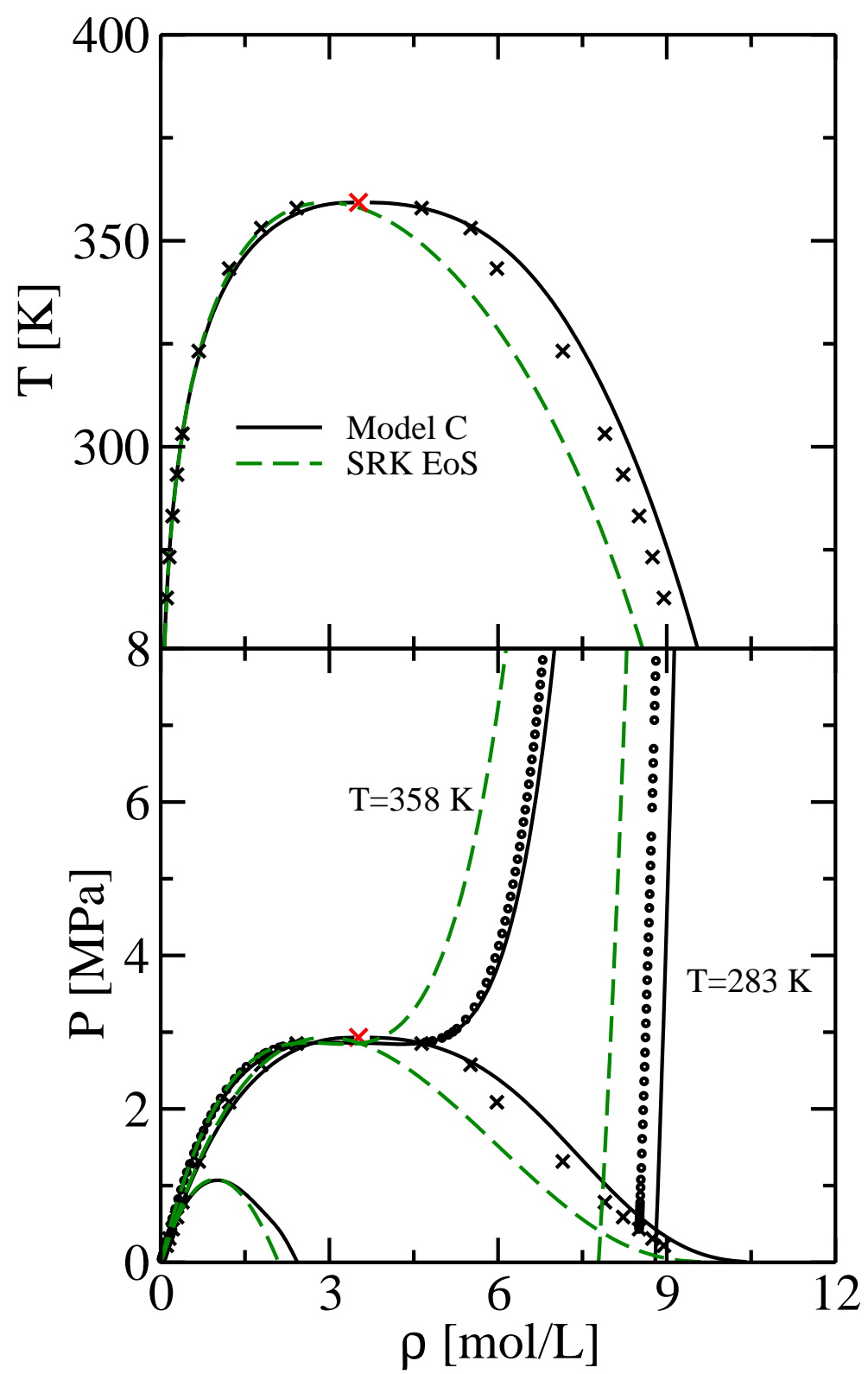

Figure 13: Phase diagram for hexafluoropropene oxide (HFPO). Model C of crossover SRK EoS (solid black lines) is compared with classical SRK EoS with parameters adjusted to reproduce the critical temperature and pressure (green dashed lines). Symbols are the experimental data [37]. 